\title{
Assessing the long-term impact of agricultural research on productivity: Evidence from France*
}

\author{
Stéphane Lemarié \\ Univ. Grenoble Alpes, INRAE, CNRS, Grenoble INP, GAEL, Grenoble, France \\ Valérie Orozco \\ Toulouse School of Economics, INRAE, University of Toulouse Capitole, Toulouse, France \\ Jean-Pierre Butault \\ INRAE-Economie Publique, Paris, France \\ Antonio Musolesi \\ Dpt. of Economics and Management and SEEDS, Univ. of Ferrara, Italy \\ Michel Simioni \\ INRAE-Moisa, Montpellier, France \\ Bertrand Schmitt \\ INRAE-CESAER, UBFC, Dijon, France
}

January 2020

\begin{abstract}
This paper analyses the economic impact of agricultural research on productivity in France over the period 1959-2012. Adopting a dynamic time series model, we provide evidence that the impact of French agricultural research is in the range of values estimated for other countries, with the estimated long-run elasticity being 0.16 , which corresponds to an internal rate of return of $22 \%$.

The estimated elasticity decreases at the beginning of the 1970s. Complementary analyses are developed to take into account the evolution of the priorities of public agricultural research (reorientation towards more fundamental objectives and focus on broader objective than productivity enhancement).
\end{abstract}

Keywords: agricultural R\&D, research lags, economic impact of agricultural research, knowledge stocks, France, dynamic time series

JEL Classification: Q16, Q18.

*The authors thank Frédéric Huard for the provision and computation of the climatic data, and Odile Hologne, Marie-Hélène Magri and Dominique Fournier for providing the bibliometric data used in this analysis. The authors also thank Alban Thomas and two anonymous referees for useful discussions and comments. We acknowledge support through the ASIRPA project funded by INRA. 


\section{Introduction}

Assessing the economic impact of publicly funded research, particularly targeted research, is of essential importance to the social debate regarding the desirability of funding research in comparison to other potential uses of public (or private) funds. Efforts to measure the profitability of agricultural research were first pioneered by Griliches (1958), who focused on hybrid corn in the USA. Since this work, many developments and empirical studies have been provided and reviewed (Evenson, 2001; Alston, 2010). These studies concluded that the impact of public research on agricultural productivity is positive and highly significant. Most studies cover Northern American or developing countries, but very few estimations have been provided for European countries. ${ }^{1}$ The first aim of this paper is to fill this gap by providing the first estimation of the impact of agricultural research on French agricultural productivity.

The French agricultural research system has several peculiar characteristics compared to the US system, which has been studied intensively. Due to the smaller size of the country, and for historical reasons, the French public research system devoted to agriculture is more centralized. Most of this public research is conducted by one institution, INRA (Institut National de la Recherche Agronomique), which has a budget of $900 \mathrm{M} €$ (approximately $80 \%$ of the USDAARS budget). Research in French universities barely addresses issues related to agriculture. Extension services are organized at the national level, each of them covering a subset of plants or animal products. As in Northern America, private agricultural research has increased over time and now represents a large share of total agricultural research, even though no precise estimation of this share is available.

Several recent research studies have analysed the evolution of the growth rate of agricultural productivity since the 1950s. For the US, several works have shown a decrease in the growth rate in the 60s (James et al., 2009) and the 90s (Ball et al., 2013). This slowdown has also been confirmed for France (Butault and Réquillart, 2012), and this paper addresses whether this change can be related to a decrease in the impact of agricultural research. Another related issue is that the priorities of public agricultural research have been evolving over time, moving from more applied research devoted to agricultural innovations to more fundamental research with diversified objectives that encompass agriculture, environmental protection, food safety and nutrition. The literature has barely analysed whether these changes have affected the estimated impact of agricultural research, and we try here to fill this gap.

In this paper, we develop an econometric analysis to estimate the impact of accumulated research investments, or the stock of knowledge, on French agricultural productivity over the period 1959-2012. Thus, we first estimate the elasticity of productivity with respect to the stock of knowledge and compare it with the estimates obtained for other countries. Second, we test whether

\footnotetext{
${ }^{1}$ In the review by Alston et al. (2000), $85 \%$ of the publications cover Northern America $(29 \%)$ and developing countries (56\%). Only $4 \%$ of the publications cover Europe.
} 
this elasticity has been changing over time. Third, we differentiate the different objectives of agricultural research (agricultural productivity, nutrition, and environment) and analyse whether the estimates are different when only considering the research investment that aims to increase agricultural productivity. Finally, we analyse whether the research lag has been increasing over time, which could cause a significant change in the estimated economic impact of research investment.

We first show that the estimation of the impact of French agricultural research is very similar to the estimated values obtained for other countries in the agricultural economics literature. We also show that the spillovers from foreign countries are significant. When considering the potential evolution of this impact over time, we show that a decrease appears at the beginning of the 70 s but that the impact has been stable since then. Finally, model estimation with increasing lag time leads to poor estimations, but considering only research investments that target productivity enhancement leads to slightly greater estimates.

This article is organized as follows. Related literature is presented in section 2 with the objective of defining three different hypotheses that will drive the empirical analysis thereafter. The French context and the data used for this analysis are presented in section 3. The methodology and results are then presented in the subsequent sections followed by the conclusion.

\section{Related literature and hypotheses}

Numerous studies on research impact have been conducted in the past fifty years, and several syntheses and meta-analyses of the results have been produced(Alston et al., 2000; Evenson, 2001; Alston, 2010). The main lesson from these numerous works is that the impact of agricultural research is quite high. For example, Alston et al. (2000) observe a median internal rate of return (IRR) of $42 \%$ using a compilation of approximately 1800 different estimates. Using the IRR as a way to measure the economic impact of research has been recently discussed in the literature (Alston et al., 2011; Hurley et al., 2014). Scholars suggest using a modified internal rate of return (MIRR) to take into account that only a small part of the benefit from research is re-invested in research. Hurley et al. (2014) recently compiled a large number of rates of return, showing a median MIRR of $9.8 \%$ instead of $39 \%$ for IRR.

One common feature across the literature is that econometric models suppose that the parameter measuring the impact of agricultural research (the elasticity of productivity with respect to the stock of knowledge) is stable over time. However, recent analyses have shown a slowdown of productivity growth in some countries, such as the US (James et al., 2009; Ball et al., 2013). Some contributions suggest that climate change may explain part of this slowdown (Brisson et al., 2010), but we can also question whether this slowdown could result from a lower impact of research. Such a decreasing impact of research would echo the general debate about the present decline in the economic impact 
of innovation on economic growth (Gordon, 2012). ${ }^{2}$

Two complementary arguments explain the possible variation in the impact over time. On the one side, the nature and organization of research and innovation has evolved over time. Several waves of technologies occurred over the last 100 years (e.g., mechanization, biotechnology, big data), and there is no reason to believe that their impact has been regular. On the other side, we have observed major changes in the general agricultural environment (climate, agricultural policy) and societal expectations with respect to agriculture (from food security to food safety and environmental concerns). These developments have led to new R\&D areas and requirements. ${ }^{3}$ In summary, there is no reason to suppose that the impact of research may be stable over time; it may decrease, increase, or both, depending on the period considered.

This discussion leads us to formulate the first hypothesis that we will address in this article.

Hypothesis 1 The impact of agricultural research may change over time, and this change can be assessed by examining the estimated elasticity of productivity with respect to the stock of knowledge and at its variation over time.

In a recent review, Alston (2010) shows that the estimates of IRR are lower in the most recent papers. However, this result can be explained by the improvements of the methodologies used and not necessarily by an actual decrease of the impact of research over time. In particular, Alston (2010) clearly shows that the most recent papers consider longer and probably more realistic lags between research investment and its impact on the knowledge stock as well as productivity. As the lag assumption has a large impact on the estimated IRR, the more recent papers inherently lead to lower IRR. ${ }^{4}$

The way to test this hypothesis will be detailed in section 4 , but we can already observe that making such a test is rather complicated. Indeed, most of the analyses are based on time series that barely cover more than 60 years (from the 1950s to the 2010s). As a consequence, one can test only for a limited change in regime.

As emphasized before, the agricultural research system has experienced large changes over time. These changes concern not only the technology but also the

\footnotetext{
${ }^{2}$ Gordon (2012) claims that the second industrial revolution (electricity, the internal combustion engine, and petroleum) was more important than the third one (computers, the web, and mobile phones). The second industrial revolution was largely responsible for 80 years of relatively rapid productivity growth between 1890 and 1972. In contrast, the third industrial revolution seems to have created only a short-lived growth revival between 1996 and 2004 but did not lead to the same growth level as the second revolution.

${ }^{3}$ We would like to thank one referee for suggesting this second argument.

${ }^{4}$ Typically, such analyses have made an assumption on the lag structure without testing alternative structures. Hence, it is not possible to know the estimation with longer and more realistic lags. The most recent works, such as Alston et al. (2010), have tested for a very large number of distributions, keeping the distribution that enables the best estimations. However, even with a more complete framework, the authors still suppose that the impact is stable over time.
} 
organization of the research system (Huffman and Just, 1999). First, while public agricultural research represented most of the investment in the 50s, this investment is now equivalent to private research investment in some countries, such as in the US (Fuglie and Toole, 2014). ${ }^{5}$ This change resulted from the drastic increase in private investment, while public research investment increased more slowly and remained stable for the past 20 years (see the next section for the case of France).

The changes in the agricultural research system also have important consequences for the nature of public research, which has progressively moved towards more fundamental objectives. Such an evolution can have impact on research lag and consequently on the rate of return of agricultural research. More precisely, one can suppose that a reorientation of public agricultural research towards more fundamental objectives would lead to an increase of research lag over time. Unfortunately, there is a lack of empirical work on both research lags and their evolution over time. ${ }^{6}$

This discussion leads to the second hypothesis, which is as follows.

Hypothesis 2 The evolution of public agricultural research toward more fundamental challenges leads to increasing research lags. As a consequence, the estimated impact of research could decrease over time.

If the first hypothesis is validated, the second hypothesis provides a possible explanation.

Public agricultural research has also experienced some important changes with regards to its objectives. These changes are consistent with the general evolution of the agricultural policies and the more general economic and political context. After the second World War, the main objective was to increase the volume of agricultural production through various types of innovation such as genetic improvement, the use of fertilizers, and mechanization. Priorities have been evolving over time because of the emergence of new stakes related to environmental protection, food safety and nutrition. To provide only one example, the recent assessment of USDA-ARS was based on the analysis of three major programs (case studies) related to genomic selection, water quality and watersheds, and a nutrient data laboratory (Heisey et al., 2010). These new stakes are not directly connected to economic aims and have a non-economic nature. Hence, these new impacts are not correctly captured in the measurement of agricultural productivity, and thus, the estimated impact is likely biased.

The diversification of the priorities of public agricultural research has generally not been taken into account in the literature on the rate of return of

\footnotetext{
${ }^{5}$ We have a much better understanding of public agricultural research compared to private agricultural research. The most important explanation is likely that datasets on private agricultural research are more complicated to build because of the multiplicity of actors.

${ }^{6}$ Some case studies conducted in France will be mentioned later, but these works only provide evidence on the lag of more recent research. Documenting the evolution of research lag over time would require having equivalent cases made over various generations of innovations since the middle of the twentieth century.
} 
agricultural research. Certain economic analyses do distinguish maintenance research in agriculture. In agriculture, various sources of problems, such as pest, may lead to productivity losses. Maintenance research covers research works that enable the maintenance of productivity. Based on a recent survey, Sparger et al. (2013) estimate that $40 \%$ of public agricultural research in the US is devoted to maintenance research, a figure that is slightly higher compared to 20 years ago. The literature that estimates the rate of return of research does not make a distinction between maintenance and productivity-increasing research. The few analyses of the impact of maintenance research are limited to some specific agricultural areas, such as wheat pest resistance (Marasas et al., 2003) and livestock production (Townsend and Thirtle, 2001).

How are research impact indicators expected to be affected if we take into account the diversification of research priorities? This question can be analysed in several ways. In this article, we disaggregate research investment into different priorities. The expected result can be summarized by the following hypothesis.

Hypothesis 3 The estimated impact of agricultural research is greater if we focus only on the research expenses devoted to the increase of agricultural productivity compared to the base case where the impact is estimated with the overall research expenses.

Note first that, by construction, the impact indicator is expected to be higher because we explain the same productivity gain with less research investment. However, as will be shown below, the impact indicator also depends on the estimation of the elasticity of productivity with respect to the stock of knowledge. Using different explanatory variables leads to different estimates of this elasticity, and there is no way to anticipate whether a new estimate will be higher or lower. Hypothesis 3 holds as long as the estimated elasticity does not decrease too much when considering only the research expenses devoted to increasing agricultural productivity (compared to the baseline case that considers all research expenses).

\section{Econometric modelling and estimation strat- egy}

\subsection{Long-run level relationship}

The model we estimate in our analysis is closely related to recent works by Alston et al. (2011) and Sheng et al. (2011).

To assess the impact of research activity on agricultural productivity, it is common practice to treat total factor productivity (TFP) as a function of research effort. Because of the lag in the research process and the cumulative nature of knowledge, we build a stock of knowledge variable that is a function of past research investments. In addition, because of the spillovers between 
countries, the French agricultural TFP is explained by both the national stock of knowledge that results from the research investment made in France and the foreign stock of knowledge. Our econometric model can be expressed as

$$
T F P_{t}=f\left(K_{t}^{F R}, K_{t}^{E X T}, \mathbf{C}_{t}\right)+\epsilon_{t}
$$

where $K_{t}^{F R}$ and $K_{t}^{E X T}$ denote local (French) and external stocks of knowledge, respectively; $C_{t}$ is a vector of other control variables that may affect TFP, such as climatic conditions; and $\epsilon_{t}$ is a random error term.

The stock of knowledge in period $t$ is defined as the accumulated past investment in research over the $L$ periods before $t:^{7}$

$$
K_{t}^{F R}=\sum_{k=1}^{L} b_{k} \cdot R \& D_{t-k}^{F R}
$$

where $b_{k}$ is the lagged effect of research investment $R \& D^{F R}$ made at a certain period on the stock of knowledge $k$ years after. Because of the limited number of observations and other constraints related to estimation methods, it is not possible to estimate this lag effect parameter $b_{k}$. As is commonly made in the literature, we hence make an assumption on the distribution of $b_{k}$ and estimate the model with alternative assumptions to retain the most relevant one. It is generally supposed (Alston, 2010) that the distribution of the $b_{k}$ should have an inverted U shape: $b_{k}$ is first increasing with $k$ because it takes some time to transform a research investment into knowledge and innovation, and $b_{k}$ is then decreasing after some time because the knowledge becomes obsolete. Following Alston et al. (2011), we use a gamma distribution with parameters $\delta$ and $\lambda$ as follows:

$$
b_{k}=\frac{k^{\frac{\delta}{1-\delta}} \cdot \lambda^{k}}{\sum_{i=1}^{L} i^{\frac{\delta}{1-\delta}} \cdot \lambda^{i}}
$$

Different distributions have been tested, and we will present a case where the peak is at 25 years $(\delta=0.9, \lambda=0.7)$ (see Figure 1$)$. The maximum duration of the lag parameter $(L)$ is equal to 50 years, but this assumption is not very important because $b_{k}$ is very small for $k=50$. Recent case studies on innovation in agriculture (Colinet et al., 2014) show that the lag between the first publication about a new technique and the first year of the diffusion of the innovation is 19.4 years on average.

To test Hypothesis 2, we also consider a series of stocks of knowledge with increasing lags to test whether the research lag may have grown during the period. To get this series, rather than considering one gamma distribution (with the same $\delta$ and $\lambda$ ) over the whole period, we consider a specific gamma distribution for each year of the period such that the peaks of the distributions increase

${ }^{7}$ The approach presented here explains how we built the French stock of knowledge. We used the same method and assumptions to build the foreign stock of knowledge. 
from year to year from a peak at 10 years to a peak at 25 years. $^{8}$

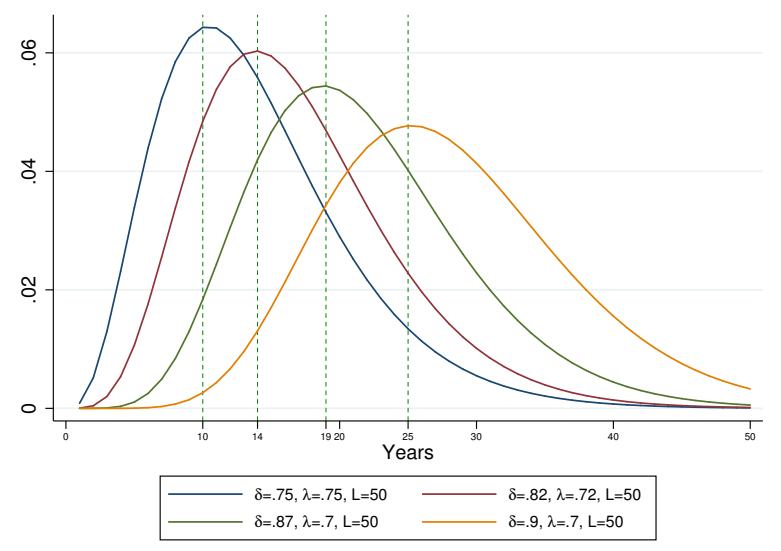

Figure 1: Some $b_{k}$ distributions

Following Sheng et al. (2011), we use US investment in public research to represent the foreign stock of knowledge because of substantial influence of American agricultural research on French agricultural research. ${ }^{9}$

In Eq. (1), estimating the impact of both the French and the foreign stock of knowledge is not possible because of the strong collinearity between these two explanatory variables. ${ }^{10}$ To address this issue, we follow the approach adopted by Sheng et al. (2011), where the stock of knowledge is defined as a linear combination of the domestic and foreign stocks:

$$
\ln \left(K_{t}^{T o t}\right)=\ln \left(K_{t}^{F R}\right)+\alpha \ln \left(K_{t}^{E X T}\right)
$$

$\alpha$ represents the accessibility and applicability of this external knowledge to the French context and depends on (i) the similarity between the two agro-ecological contexts and (ii) the share of imports from the US to France. The application of this definition leads us to consider $\alpha=0.25 .{ }^{11}$ For comparison with the case where spillovers are ignored, we also make the estimation with $\alpha=0$.

\footnotetext{
${ }^{8}$ More precisely, $\delta$ and $\lambda$ vary linearly from $(0.75,0.75)$ at the beginning of the period, to $(0.9,0.7)$ at the end of the period (see Figure 1$)$.

${ }^{9}$ Historical analysis reveals that several major innovations introduced in France during the period of interest (e.g., hybrid corn, milk cow breeding methods) were based substantially on US research (Cornu et al., 2018). More broadly, an analysis of agriculture-related academic publications and citations shows a major contribution of the US to global scientific production until the beginning of the 2000s, which corresponds to the period studied in this article (computations made from the Web of Science are available from the author upon request).

${ }^{10}$ Indeed, in our data, the correlation between the French and the foreign (US) stocks of knowledge is high (a correlation coefficient of 0.9578).

${ }^{11}$ We tested alternative levels of spillovers $(\alpha=0.15 ; 0.20$ and 0.25$)$ and get very robust estimations. Here, we present only estimations with $\alpha=0.25$, which provides the best fit to the data.
} 
Finally, we choose a $\log$-log form for $f($.$) in Eq. (1) to directly interpret the$ estimated parameters as elasticities. The long-run equation to be estimated can now be written as follows:

$$
\ln \left(T F P_{t}\right)=\theta_{0}+\theta_{1} t+\theta_{2} \ln \left(K_{t}^{T o t}\right)+\theta_{3}^{\prime} \ln \left(\mathbf{C}_{t}\right)+\nu_{t} .
$$

\subsection{Causality issues}

Note that we assume a unidirectional causal link from the stock of knowledge to productivity. Eq. (5) is inspired by the so-called knowledge production function (see, eg., Griliches (1998), p. 1671), and this is a common specification in macroeconometric works (Wang et al., 2013; Balcombe et al., 2005), as the main focus is testing for the existence of a long-run R\&D-TFP relationship against the possible presence of a spurious relation due to common stochastic trends (see, e.g., Alston et al. (2011)). In the proposed framework, a valid statistical analysis requires the R\&D stock to be weakly exogenous.

A few studies have also attempted to address the issue of the possible existence of reverse causality. At a macroeconometric level, using time series or large panel data sets, this question has been addressed by using Granger causality tests, and within this framework, there is empirical support for a unidirectional link from R\&D to productivity (Rouvinen, 2002; Khan et al., 2017).

It is well known, however, that Granger causality does not strictly refer to the concept of causality (Hendry, 2004, 2017), but it does refer to the idea of temporal precedence, as it assesses "the presence or absence of feedbacks in a limited data set, irrespective of whether or not they are genuine data generation process (DGP) causes" (Mizon and Hendry, 1998). Moreover, it can be shown that 'Granger non-causality' is equivalent to strong exogeneity (Pagan and Wickens, 1989).

Finally note that Granger causality also differs from the concept of causality used in microeconometrics, without further assumptions (Lechner, 2010). Indeed, if the main goal is to address the issue of a firm's endogenous decision to engage in $R \& D$ investment, econometric modelling, now based on firm-level data, must account for the fact that this investment decision may be affected by past productivity shocks, as proposed by Olley and Pakes (1996), Levinsohn and Petrin (2003), or Doraszelski and Jaumandreu (2013).

\subsection{Dynamic representation and testing for a long-run level relationship}

In this paper, we adopt a dynamic econometric model that allows us to assess the existence of a long-run level relation. To the best of our knowledge, few empirical studies analysing the research impact on agricultural productivity use econometric approaches that capture the dynamics of the studied series and their long-run relationship. Sheng et al. (2011) used an autoregressive integrated moving average (ARIMA) time series specification, which avoids OLS estimation that can fail to take into account the time series properties of the data and may 
estimate a spurious relationship but does not take into account the dynamics and link between the two series of interest. Alston et al. (2011) use an Engel and Granger error-correction model (ECM) that captures the long-run relationship and dynamics, but this model requires the variables of interest to be first-order integrated, which is not always the case.

The econometric framework we adopt is an ARDL (autoregressive distributed lag) model, and more specifically, we use the approach developed by Pesaran and Shin (1999) and Pesaran et al. (2001). This approach is very useful for our research objectives, as it allows for testing and estimating the existence of a long-run relationship between productivity and stock of knowledge while considering both long- and short-term productivity dynamics and the speed of adjustment towards the equilibrium. Indeed, in the ARDL specification, the parameter associated with the autoregressive component indicates the persistence of the series, while the parameter associated with the ECM term gives useful information on adjustment dynamics to the long-run equilibrium. Second, the long-run estimated parameters provide the long-run elasticity of TFP with respect to knowledge stock. Third, the ARDL specification allows comparing long-run and short-run estimated parameters. Finally, the ARDL specification is a suitable framework for estimating a model irrespective of the degree of integration of the variables of interest.

Following Pesaran et al. (2001), we consider an ARDL conditional ECM model defined as follows:

$$
\begin{aligned}
\Delta \ln T F P_{t}= & \begin{array}{c}
a_{0}+a_{1} t+\phi \ln T F P_{t-1}+\eta^{\prime} \ln \left(\mathbf{x}_{t-1}\right) \\
+\sum_{i=1}^{p-1} \psi_{i} \Delta \ln T F P_{t-i}+\sum_{i=0}^{p} \varphi_{i}^{\prime} \Delta \ln \left(\mathbf{x}_{t-i}\right)+\epsilon_{t}
\end{array}
\end{aligned}
$$

where $\ln T F P_{t}$ is a scalar variable representing the natural logarithm of TFP in year $t$ and $\mathbf{x}$ is a $\mathrm{k}$-vector of explanatory variables that includes the stock(s) of knowledge and possibly other control variables, i.e., $\ln \left(\mathbf{x}_{t}^{\prime}\right)=\left[\ln \left(K_{t}^{T o t}\right), \ln \left(\mathbf{C}_{t}^{\prime}\right)\right]$. It follows from (6) that if $\phi \neq 0$ and $\eta \neq 0$, there exists a conditional level relationship between $T F P_{t}$ and $\mathbf{x}_{t}$, which corresponds to the long-term equation determining the TFP, which can be expressed as:

$$
\ln T F P_{t}=\theta_{0}+\theta_{1} t+\theta_{4}^{\prime} \ln \left(\mathbf{x}_{t}\right)+\nu_{t}
$$

where $\theta_{0} \equiv-\frac{a_{0}}{\phi}, \theta_{1} \equiv-\frac{a_{1}}{\phi}, \theta_{4} \equiv-\frac{\eta}{\phi}$, is a k-vector of long-run response parameters, and $\left\{\nu_{t}\right\}$ is a zero-mean stationary process. Equation (6) can be reformulated in ECM form as follows:

$$
\begin{aligned}
\Delta \ln T F P_{t}= & a_{0}+a_{1} t+\zeta\left(\ln T F P_{t-1}-\theta_{4}^{\prime} \ln \left(\mathbf{x}_{t-1}\right)\right) \\
& +\sum_{i=1}^{p-1} \psi_{i} \Delta \ln T F P_{t-i}+\sum_{i=0}^{p} \varphi_{i}^{\prime} \Delta \ln \left(\mathbf{x}_{t-i}\right)+\epsilon_{t}
\end{aligned}
$$

where $\zeta$ represents the speed of adjustment to the long-run equilibrium. $\zeta$ typically lies in the range $[-1,0]$. If $\zeta=0$, there is no adjustment to the long-run 
equilibrium. If $\zeta<0$, then the long-run relationship between the levels of $T F P_{t}$ and $x_{t}$ is stable since there is adjustment to the long-run equilibrium. For example, for $\zeta=-1$, the disequilibrium in the previous year is completely corrected in the current year.

According to Pesaran and Shin (1999) and Pesaran et al. (2001), the ARDL modelling approach to cointegration requires the following two steps. In the first step, the absence of any long-run relationship between $T F P_{t}$ and $x_{t}$ is tested through exclusion of the lagged level variables $T F P_{t-1}$ and $\mathbf{x}_{t-1}$ in equation (6). This ARDL bound test, which analyses the existence of a level relationship, consists of testing $H_{0}: \phi=\eta=0$ (no cointegration) in equation (6) and is based on the Wald-test (F statistic). Critical values of the test statistics are tabulated in Pesaran et al. (2001) and in Narayan (2005) for smaller sample sizes. ${ }^{12}$

In the second step of the analysis, following estimation of the ARDL model defined by (6), which gives the short-run impacts, we obtain the long-run parameters of (7) from the coefficients of the lagged variables of (6). Finally, by re-parameterising (6), the ECM model (8) is estimated, and the speed of adjustment to the equilibrium is determined.

Furthermore, this specification allows us to calculate some economic performance indexes. Indeed, since we have a log-log specification, the estimated parameter $\widehat{\theta}_{2}$ is the estimated long-run elasticity of TFP with respect to knowledge. We can then calculate some standard economic performance measures of research investment such as the IRR, and its modified version (MIRR), and the benefit-cost ratio (BC) (see Appendix B for details on the formula). ${ }^{13}$

\section{Data for the French case}

Due to data availability, our investigation focuses on the impact of public spending in agricultural research on the productivity of French agriculture and thus excludes the effects on the food processing industry and food consumption. We first build a TFP series for the period 1959-2012 on the basis of agricultural production and inputs (capital and labour). We then complete the series with public research spending in France for the period 1946-2013.

\footnotetext{
${ }^{12}$ If the $\mathrm{F}$ statistic is higher than the upper bound at $95 \%$ or $90 \%$, we can say that there is cointegration among the set of $\mathrm{I}(0)$ and $\mathrm{I}(1)$ variables, so we can assume that there can be at least a long-run or short-run relation among these variables. If this $\mathrm{F}$ statistic is not higher than any of the upper-bound critical values, there is no cointegration. Finally, in case the F statistic falls between bounds, the test is inconclusive.

${ }^{13}$ For all empirical estimations, we use Stata 15.1 and its ardl command (version 1.0.2; see Kripfganz and Schneider (2016)). For the bounds test, we consider critical values from Narayan (2005) adapted for small sample sizes.
} 


\subsection{Agricultural productivity}

The estimated TFP and productivity surplus of French agriculture are based on data from national accounts for the period 1959-2012. The productivity index is defined as the ratio between the volume of output and the volume of production factors. The Fisher chained index is used with aggregated production output and input volumes (intermediate consumption, capital, land, and labour). ${ }^{14}$ The relationship between research and productivity cannot be studied without taking into account improvements in human capital. As a consequence, human capital was incorporated directly into our measurements of productivity by using a labour quality index based on the training received by farm managers and the qualifications of agricultural workers. However, over inputs are not quality adjusted.

Over the period considered here, 1959-2012, the annual growth rate of French overall agricultural productivity is found to be $1.5 \%$ per year (see Figure 2 and Butault et al. (2015)). This figure can be disaggregated into an annual increase in French agricultural output of $1.2 \%$ per year and a decrease in the aggregate volume of production factors of $0.3 \%$. Some historical elements of context should briefly be reminded here. From 1959 until the beginning of the 1990s, the European Common Agricultural Policy (CAP) aimed to increase the volume of agricultural production with the intensive use of inputs. The oil shock in 1973 led to temporary decreases in productivity, and between 1974 and 1999, the overall productivity tended to increase somewhat faster. During this period, the annual growth rate of agricultural outputs was entirely offset by the improvement of partial productivities. Finally, the volume of agricultural output remained stable after 1999, and a certain decline in productivity gains can be observed. The stabilization of agricultural production is consistent with first CAP reform in the 1980s and the other major reforms since the 1990s. The former was intended to moderate the incentive to increase production, and the more recent reforms placed greater emphasis on moderating input use and the related environmental impact.

\subsection{Public agricultural research investments}

The national agricultural accounts provide an annual assessment of public subsidies to agriculture. This time series, covering the 1987-2013 period, includes all national and European payments to agriculture and food processing industries, including funding for research and development activities (R\&D). This infor-

\footnotetext{
${ }^{14}$ See Diewert (1993) for a presentation of Fisher index and derivation of its properties. Diewert (1993) provides strong justifications for the use of the Fisher productivity index from the viewpoint of economic theory. Details on its computation in the French agriculture case are provided in Butault et al. (2015). As many other indexes, the use of the Fisher index for estimating TFP can be problematic, especially when used in cross-section because it does not meet the transitivity condition (Ball et al., 1997; Diewert and Fox, 2017). However, it can be assumed that this issue is less crucial when the index is used in a time series approach. Indeed, in this case, the Fisher chained index can be seen as an approximation of the productivity estimate in a continuous framework, that is, an approximation of Divisia indexes.
} 


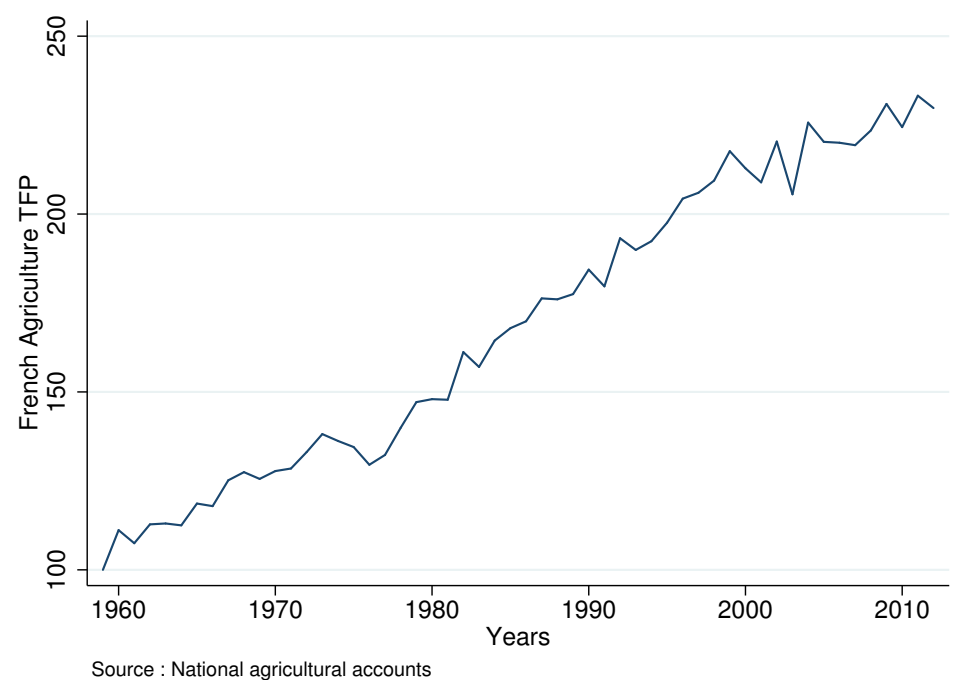

Figure 2: Overall productivity of French agriculture (TFP, base 100=1960)

mation was supplemented by the historical work of Alphandery et al. (1989), leading to a final time series covering 1946-2013. This public support for agricultural R\&D covers only basic government funding for general operations and investments, most of which are devoted to salaries within public research organizations. These data therefore do not include grant funding of public research organizations (of which $90 \%$ come from public sources), credits allocated to higher education establishments in agronomy, R\&D credits allocated to professional bodies and extension services, or the $\mathrm{R} \& \mathrm{D}$ spending of companies in the agricultural and food processing sectors. We estimate that this indicator covers approximately $60 \%$ of R\&D spending in these sectors and focuses specifically on public research spending. Figure 3 synthesizes the evolution of this agricultural investment, which increases from 7 million Euros in 1945 to 740 million Euros in 2013. A slowdown in the upward trend can be observed towards the end of the period.

In France, public agricultural research is concentrated in some specific (public) research agencies ${ }^{15}$, extension services and (agronomy) engineering schools. Agriculture-related research is poorly represented in French universities and general public research agencies such as CNRS (National Center for Scientific Research). The most important research organization is INRA, which was created in 1946. The research priorities at INRA have been evolving over time in

\footnotetext{
${ }^{15}$ The main public agricultural research institutes in France are the INRA (French National Institute for Agricultural Research), IRSTEA (National research institute of science and technology for environment and agriculture), CIRAD (Agricultural Research for Development), IRD (Research Institute for Development) and IFREMER (French Research Institute for Exploitation of the Sea)
} 


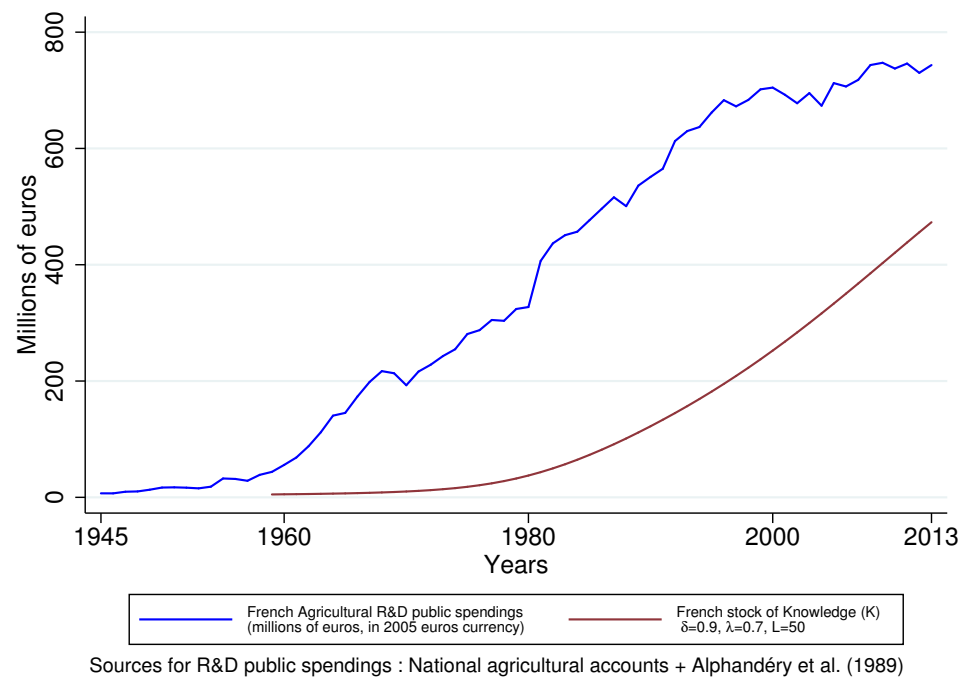

Figure 3: French public agricultural R\&D spending (millions of 2005 euros) and stock of knowledge

accordance with our hypothesis 3 . More specifically, the main priorities over the past 20 years have been agricultural production, environment and food. Fifty years ago, the enhancement of agricultural production was by far the most important priority compared to the development of the food production and food processing industries. At the same time, the research devoted to environment, food consumption, and nutrition issues was only very marginal. The French accounting system does not enable splitting public research investment among these different priorities. Hence, we build two proxies based, first, on the distribution of employees among research divisions at INRA and, second, the distribution of publications of INRA scientists across subject categories. Appendix A.2 provides more details about the construction of these two proxies. The employee-related proxy is available for the whole time series, while the publication related proxy is available only from 1981.

Figure 4 presents the shares of research among the priorities using these two proxies. Between 1946 and the end of the 1970s, the agricultural priority remained stable, representing between $75 \%$ and $80 \%$ of the total research investment. This priority then decreases to $55 \%$ until the recent period. Half of the $20 \%$ decrease in the agricultural priority over the past 30 years is related to the emergence of the environment priority (which increased from 5\% to 15\%), while the other half is related to the increase of the food priority (from $20 \%$ to $30 \%)$. 


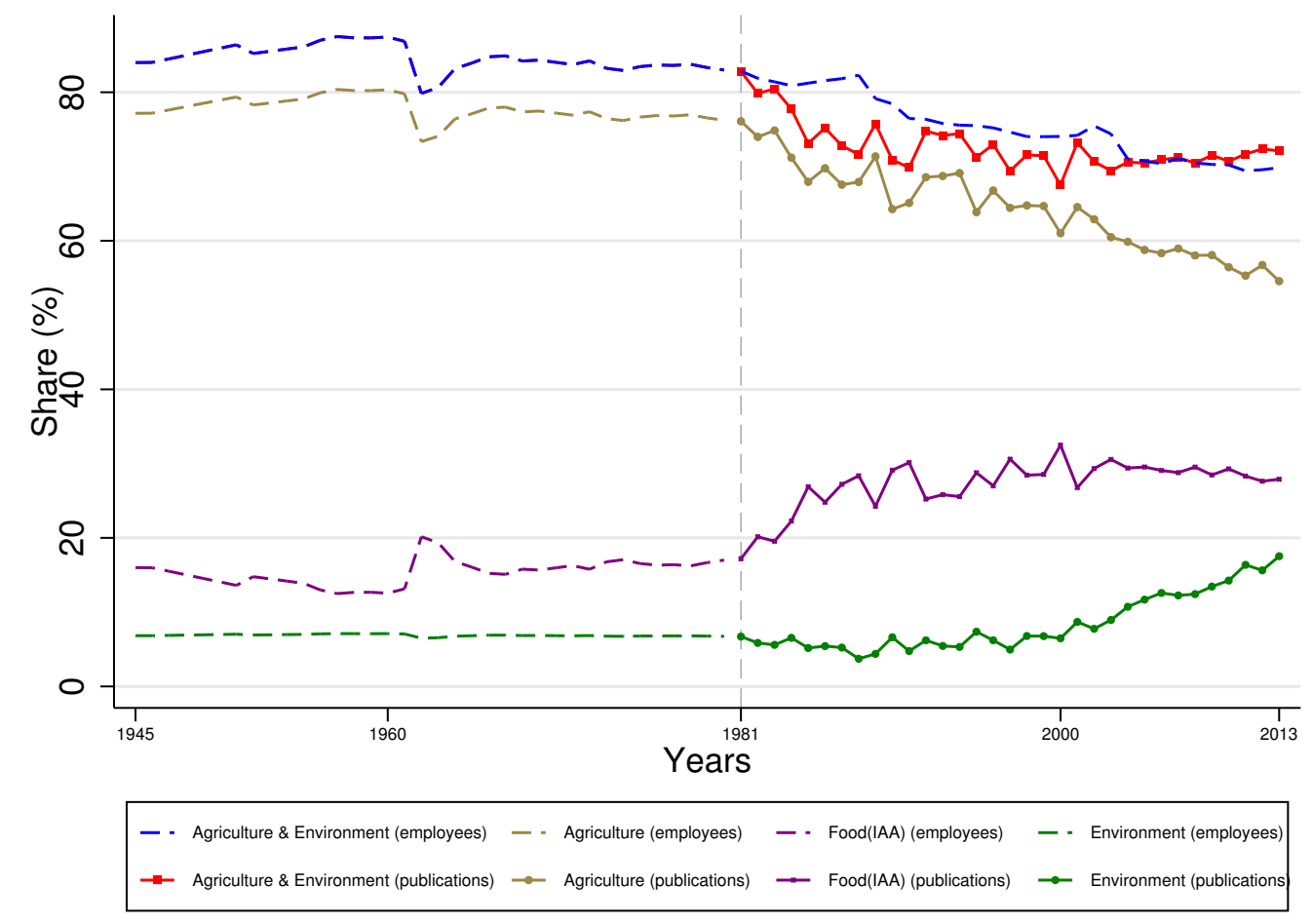

Figure 4: Evolution of the distribution of research priorities

\subsection{Other explanatory variables}

In addition to the French knowledge stock, we also use the US knowledge stock and some climate proxies as explanatory variables. The US stock of knowledge is used as a proxy to represent the foreign stock of knowledge, following Sheng et al. (2011). This variable is computed from the research investment taken from Alston et al. (2010), using the same assumption as that used to build the French stock of knowledge.

Agricultural productivity can be affected by variations in climatic conditions from year to year and by the recent climate warming trend. The climatic variables were compiled at the national level with data from Météo-France (SAFRAN database). The following four variables were compiled: radiation, rainfall, temperature and the difference between rainfall and evapotranspiration. More details concerning the method used to compile these variables are given in appendix A.1. In addition to these climatic variables, we also used the pasture productivity index as in Alston (2010) because its variation over time is mainly caused by climatic variation. We obtained this index from the statistical service of the French Ministry of Agriculture. 
Table 1: Synthesis of all estimated models

\begin{tabular}{|c|c|c|c|}
\hline \multirow[t]{2}{*}{ Lag distribution } & \multirow{2}{*}{$\begin{array}{l}\text { Agricultural research } \\
\text { priorities }\end{array}$} & \multicolumn{2}{|c|}{ Spillovers } \\
\hline & & $\alpha=0$ & $\alpha=0.25$ \\
\hline Constant (peak at 25 years) & All & Model 1 & Model 1' \\
\hline Increasing lags (peak from 10 to 25 ) & All & Model 2 & Model 2' \\
\hline Increasing lags (peak from 15 to 25 ) & All & Model 3 & Model 3' \\
\hline Constant (peak at 25 years) & $\begin{array}{l}\text { Agriculture } \\
\& \text { Environment } \\
\text { (employees) }\end{array}$ & Model 4 & Model 4' \\
\hline Constant (peak at 25 years) & $\begin{array}{l}\text { Agriculture } \\
\text { (publications) }\end{array}$ & Model 5 & Model 5' \\
\hline
\end{tabular}

\section{Estimation results}

The econometric framework presented previously has been applied on our French dataset covering the period 1959-2012. Different models were estimated, and their characteristics are summarized in Table 1.

First, we consider a model defined by a distribution of research lag with a peak at 25 years $\left(\delta=0.9, \lambda=0.7\right.$ in Eq. (3)). Two models ( 1 and $\left.1^{\prime}\right)$ are first estimated depending on whether the spillovers from the foreign stock of knowledge are taken into account. These first two models allow us to investigate Hypothesis 1.

Then, to investigate Hypothesis 2, we use different gamma distributions allowing for increasing lags (models 2, 2', 3 and 3'). Finally, we incorporate different measures of knowledge to capture the evolution of research priorities and test the impacts (models $4,4^{\prime}, 5$ and $5^{\prime}$ ). This approach will thus allow us to investigate Hypothesis 3.

\subsection{Results from common specifications}

We start by presenting the estimation with assumptions commonly made in the literature (models 1 and 1'). The stock of knowledge corresponds to the overall investment in public agricultural research. The prime objective here is to compare estimation results for France, which has never been done before, with those available in the literature for other countries. 
Alternative lag distributions have been considered, and the distribution with a peak at 25 years leads to the best econometric estimates. ${ }^{16}$ This result is consistent with Alston et al. (2011) and is also consistent with the empirical evidence from different case studies conducted for France by Colinet et al. (2014). Indeed, based on 30 innovations originating from public agricultural research (INRA), this analysis shows that on average, there is a lag of 19.4 years from the first publication until the observed start of the impact, including all the intermediary stages leading to the innovation. Adding a few years to capture the diffusion of the innovation, and thus getting a peak of the economic impact after 25 years, is rather realistic.

We retain an $\operatorname{ARDL}(2,0,0)$ specification without any time trend and adding climatic variable as control variables. ${ }^{17}$ The 'basic' ARDL can be written as follows:

$$
\ln T F P_{t}=a_{0}+\gamma_{1} \ln \left(T F P_{t-1}\right)+\gamma_{2} \ln \left(T F P_{t-2}\right)+\beta_{1} \ln \left(K_{t}^{T o t}\right)+\ln C_{t}+\epsilon_{t}
$$

while the corresponding conditional ECM (see equation (8)) is

$$
\begin{gathered}
\Delta \ln T F P_{t}=a_{1}+\zeta\left[\ln T F P_{t-1}-\theta_{2} \ln \left(K_{t-1}^{T o t}\right)-\theta_{3}^{\prime} \ln \left(C_{t-1}\right)\right]+\psi_{1} \Delta \ln T F P_{t-1}+ \\
\varphi_{1} \Delta \ln \left(K_{t}^{T o t}\right)+\varphi_{2} \Delta \ln \left(C_{t}\right)+\epsilon_{t} .
\end{gathered}
$$

The first part of Table 2, entitled "ARDL", summarizes the results from the estimation of the "basic" ARDL (Eq. 9), giving the dynamic behaviour of the series. The results from the estimation of the conditional ECM (Eq. 10), giving both short-run effects and the speed of adjustment to the long-run equilibrium and long-run parameters, are presented in the "ECM" and "ECM_LR" parts of the table, respectively.

We first estimate a model considering only the French stock of knowledge $(\alpha=0)$ (model 1 of Table 2). The parameters associated with the lagged variables that correspond to productivity at $t-1$, denoted by L.lnTFP, and at $t-2$, denoted by L2.InTFP, are positive and significantly different from zero. Therefore, the productivity at $t$ is positively influenced by the productivity of the two preceding years. Moreover, the estimated parameter of the French stock of knowledge, which is the elasticity of the productivity with respect to the stock of knowledge, is positive and significantly different from zero both in

\footnotetext{
${ }^{16}$ We tested alternative lag distributions with peaks at $10,12,15$, and 25 years. The details of these analyses are not presented in the paper but are available upon request. For peaks at 10, 12, and 15, the $\mathrm{F}$ statistic was below the threshold of significance, meaning that the null hypothesis of no long-run relationship is not rejected. We thus choose the distribution of research lag with a peak at 25 years, for which the $\mathrm{F}$ statistic is significant, meaning that there is cointegration and that adjustment towards a long-term equilibrium is faster.

${ }^{17}$ Indeed, we tested the model with a yearly time trend like in Eq. (8), but the corresponding coefficient was not significant. We also tested models without the climatic control variables, and the results are highly robust. Concerning the choice of the ARDL orders, we use standard criteria such as AIC and BIC, bearing in mind the need to have a parsimonious model.
} 
Table 2: Estimated results for overall agricultural research with constant lag

\begin{tabular}{|c|c|c|c|c|}
\hline ARDL & \multicolumn{2}{|c|}{$\begin{array}{c}\text { Model } 1 \\
\quad(\alpha=0)\end{array}$} & \multicolumn{2}{|c|}{$\begin{array}{l}\text { Model 1' } \\
(\alpha=0.25)\end{array}$} \\
\hline $\begin{array}{l}\text { L.lnTFP } \\
\text { L2.lnTFP } \\
\operatorname{lnK} \\
\text { lnDif_R_ETP } \\
\text { _cons }\end{array}$ & $\begin{array}{l}0.230^{*} \\
0.376^{* * *} \\
0.062^{* * *} \\
0.007^{* *} \\
1.742^{* * *} \\
\end{array}$ & $\begin{array}{l}(0.124) \\
(0.111) \\
(0.019) \\
(0.003) \\
(0.501) \\
\end{array}$ & $\begin{array}{l}0.226^{*} \\
0.370^{* * *} \\
0.059^{* * *} \\
0.007^{* *} \\
1.689^{* * *}\end{array}$ & $\begin{array}{l}(0.124) \\
(0.111) \\
(0.018) \\
(0.003) \\
(0.480)\end{array}$ \\
\hline $\begin{array}{l}\text { ECM } \\
\text { adj } \\
\text { LD.lnTFP } \\
\text { D.lnK } \\
\text { D.lnDif_R_ETP }\end{array}$ & $\begin{array}{l}-0.394^{* * *} \\
-0.376^{* * *} \\
0.062^{* * *} \\
0.007^{* *}\end{array}$ & $\begin{array}{l}(0.113) \\
(0.111) \\
(0.019) \\
(0.003) \\
\end{array}$ & $\begin{array}{l}-0.404^{* * *} \\
-0.370^{* * *} \\
0.059^{* * *} \\
0.007^{* *} \\
\end{array}$ & $\begin{array}{l}(0.115) \\
(0.111) \\
(0.018) \\
(0.003) \\
\end{array}$ \\
\hline $\begin{array}{l}\text { ECM_LR } \\
\text { lnK } \\
\text { lnDif_R_ETP } \\
\text { _cons }\end{array}$ & $\begin{array}{l}0.157^{* * *} \\
0.018^{*} \\
4.423^{* * *}\end{array}$ & $\begin{array}{l}(0.007) \\
(0.010) \\
(0.043)\end{array}$ & $\begin{array}{l}0.146^{* * *} \\
0.018^{*} \\
4.182^{* * *}\end{array}$ & $\begin{array}{l}(0.006) \\
(0.010) \\
(0.047)\end{array}$ \\
\hline $\begin{array}{l}\text { Observations } \\
\text { ARDL R-squared } \\
\text { ECM R-squared } \\
\text { F-statistic }\end{array}$ & $\begin{array}{l}51 \\
0.990 \\
0.471 \\
12.068^{* *}\end{array}$ & & $\begin{array}{l}51 \\
0.990 \\
0.473 \\
12.288^{* *}\end{array}$ & \\
\hline $\begin{array}{l}\text { IRR } \\
\text { BC } \\
\text { MIRR }\end{array}$ & $\begin{array}{l}22.4 \\
28.223 \\
10.164\end{array}$ & & $\begin{array}{l}21.9 \\
26.279 \\
10.007\end{array}$ & \\
\hline
\end{tabular}

Standard errors in parentheses.

$\mathbf{L}$ and $\mathbf{D}$ are the standard time series operators (resp. lag and difference).

The considered stock of knowledge is $\ln \left(K_{t}^{T o t}\right)=\ln \left(K_{t}^{F R}\right)+\alpha * \ln \left(K_{t}^{U S}\right)$

Dif_R_ETP : Difference between Rainfall and Evapotranspiration.

The MIRR and $\mathrm{BC}$ are calculated assuming a $3 \%$ per year real discount rate.

${ }^{*} p<0.10,{ }^{* *} p<0.05,{ }^{* * *} p<0.01$ 
the short run and the long run. Finally, the F statistic validates the existence of the long-term relationship. ${ }^{18}$ A second model that includes the spillovers from the foreign knowledge, captured here with the US stock of knowledge ( $\alpha=$ 0.25 ), is also estimated (model 1'). Including the spillovers from foreign research leads to similar results of 0.059 instead of 0.062 for the short-run elasticity and 0.146 instead of 0.157 for the long-run elasticity. The lower estimated elasticities confirm that ignoring the spillovers from the foreign countries leads to an overestimation of the impact of the local stock of knowledge. The adjustment towards the long-term equilibrium (-0.394 or -0.404) and the F statistic are also quite similar with this alternative specification. The climate proxy we add as a control variable is the difference between rainfall and evapotranspiration. The effect of including this proxy has the expected sign and is significant at the $5 \%$ level. ${ }^{19}$

We perform some diagnostic tests to assess the validity of the estimated models. First, to validate our analysis, we assess whether the hypothesis of the exogeneity of the stock of knowledge is verified. A test of weak exogeneity of $\ln K_{t}$ indicates that $\ln K_{t}$ is weakly exogenous (see Appendix $\mathrm{C}$ for further details concerning test implementation and results).

Then, the Lagrange multiplier (LM) test for autocorrelation (see table 4) suggests that the residuals are not serially correlated. ${ }^{20}$ According to the JarqueBera test (see table 3), the null hypothesis of normally distributed residuals cannot be rejected at the usual significance levels. The Breusch-Pagan heteroscedasticity test suggests the homoscedasticity of the residuals. Finally, the Ramsey RESET test suggests that the model is well specified.

Table 3: Post-estimation test of residuals (Model 1)

\begin{tabular}{lll}
\hline \hline Breusch-Godfrey LM test for autocorrelation & chi2(1)=2.08 & pvalue $=.15$ \\
Skewness and kurtosis test for normality & chi2 $=1.66$ & pvalue $=.44$ \\
Breusch Pagan heteroscedasticity test & chi2 $(1)=.99$ & pvalue $=.32$ \\
Functional form Ramsey's RESET test & $\mathrm{F}(3,43)=1.03$ & pvalue $=.39$ \\
\hline \hline
\end{tabular}

The results on the elasticity of French agricultural productivity in relation to the stock of knowledge are very robust. More precisely, from the long-run estimated values, we obtain an estimated elasticity varying between 0.15 and 0.16 and that is always significantly different from zero at the $1 \%$ significance

\footnotetext{
${ }^{18}$ Indeed, the significance of the $\mathrm{F}$ statistic indicates that the null hypothesis of no level effect (no cointegration) is rejected. Thus, there is cointegration.

${ }^{19}$ The results both with and without this climate control variable are robust. Several climate variables have been used (grass productivity, the difference between rainfall and evapotranspiration, radiation, rain, and the sum of temperatures). We keep the difference between rainfall and evapotranspiration because this variable has the most significant impact and its introduction in the model leads to the best $\mathrm{F}$ statistic.

${ }^{20}$ Here, we present the results of the tests for model 1 . This test was performed for all the estimated models and gave similar conclusions.
} 
Table 4: LM test for autoregressive conditional heteroskedasticity (ARCH)

\begin{tabular}{lcccccccc}
\hline \hline & 1 & 2 & 3 & 4 & 5 & 6 & 7 & 8 \\
\hline chi2 & 0.04 & 0.75 & 1.76 & 2.65 & 3.18 & 4.55 & 6.96 & 7.36 \\
pvalue & 0.83 & 0.69 & 0.62 & 0.62 & 0.67 & 0.60 & 0.43 & 0.50 \\
\hline \hline
\end{tabular}

level. In other words, an increase of $1 \%$ in the stock of knowledge made available to French agriculture generated by successive waves of public investment in agricultural research ${ }^{21}$ has led to a long-term increase in the TFP of French agriculture of approximately $0.15 \%$. Using these results, we can compute different economic indicators describing the impacts of public research spending on the level of French agricultural productivity (at the bottom of table 2). The detailed definition of these performance measures is provided in Appendix B. A value of the elasticity in the range of $0.15-0.16$ leads to an internal rate of return (IRR) of approximately $22 \%$. This level of IRR, which may seem high, is of the same order of magnitude as those obtained in most international studies (Alston et al., 2000). Similarly, we obtain an MIRR of $10 \%$ and a BC of 26 . These two indicators are also in the range of the estimated values found in the literature and show a rather similar general level of impact of French agricultural research compared to that of other countries. ${ }^{22}$

\subsection{Stability of knowledge elasticity over time}

In line with hypothesis 1 , we now analyse the stability of the elasticity of knowledge over time. To do so, we consider a specification that is a modified version of models 1 and 1' presented above and in which the full period (1959-2012) is divided in two successive periods $P_{1}$ an $P_{2}$. A dummy variable indicating the corresponding period $1_{\left\{t \in P_{2}\right\}}=1$ if $t \in P_{2}$ and 0 if $t \in P_{1}$ is created. In the specification of the model, the stock of knowledge is interacted with this dummy variable, leading to a short-run and long-run estimated elasticity that are specific to each sub-period. The number of years in the dataset prevents us from considering more than two different sub-periods. Equation 8 becomes:

$$
\begin{aligned}
\Delta \ln T F P_{t}= & a_{0}+a_{1} t+\zeta\left[\ln T F P_{t-1}-1_{\left\{t \in P_{1}\right\}} \theta_{1}^{\prime} \ln \left(x_{t-1}\right)-1_{\left\{t \in P_{2}\right\}} \theta_{2}^{\prime} \ln \left(x_{t-1}\right)\right] \\
& +\sum_{i=1}^{p-1} \psi_{i} \Delta \ln T F P_{t-i}+\sum_{i=0}^{p} 1_{\left\{t \in P_{1}\right\}} \varphi_{i}^{\prime 1} \Delta \ln \left(x_{t-i}\right) \\
& +1_{\left\{t \in P_{2}\right\}} \varphi_{i}^{\prime 2} \Delta \ln \left(x_{t-i}\right)+\epsilon_{t}
\end{aligned}
$$

\footnotetext{
${ }^{21}$ The stock of knowledge results from the weighted sum of research investments over the past 50 years. A $1 \%$ increase in the research investment over these 50 years leads to a $1 \%$ increase in the stock of knowledge. If we consider the stock of knowledge in 2012, this represents an increase from 87.9 to 88.8 million euros in $1962, \ldots$, and from 746.1 to 753.5 in 2011 . The cumulative sum of these additional investments over 50 years reaches 234.81 million euros.

${ }^{22}$ Hurley et al. (2014) re-compile a large range of MIRRs from the literature. A $10 \%$ MIRR corresponds to the first (lower) quartile, and the median is equal to $13.3 \%$.
} 
The model with no breaks in the slope parameters is tested against the model with breaks by using a conventional F-type test statistic. Rather than imposing a single date of the break, we test a break in the slope for every year in the sample.

Table 5: Estimated LR elasticities from models 1 and 1' considering two subperiods and test of equality

\begin{tabular}{lcccccc}
\hline \multicolumn{1}{c}{ Year y } & \multicolumn{5}{c}{$\alpha=0$} \\
& $\widehat{\theta}^{P_{1}}$ & $\widehat{\theta}^{P_{2}}$ & $\mathrm{~F}$ & $\widehat{\theta}^{P_{1}}$ & $\widehat{\theta}^{P_{2}}$ & $\mathrm{~F}$ \\
\hline $1965, \ldots, 1972$ & & \multicolumn{5}{c}{ Non-significant difference } \\
1973 & 0.191 & 0.169 & $3.19^{*}$ & 0.169 & 0.157 & $3.01^{*}$ \\
1974 & 0.215 & 0.178 & $21.51^{* * *}$ & 0.185 & 0.166 & $19.77^{* * *}$ \\
1975 & 0.218 & 0.181 & $36.22^{* * *}$ & 0.190 & 0.169 & $35.99^{* * *}$ \\
1976 & 0.209 & 0.178 & $14.42^{* * *}$ & 0.186 & 0.168 & $19.46^{* * *}$ \\
1977 & 0.195 & 0.172 & 2.59 & 0.180 & 0.164 & $5.37^{* *}$ \\
$1978, \ldots, 2007$ & & \multicolumn{5}{c}{ Non-significant difference } \\
\hline
\end{tabular}

Year y defines the two sub-periods $P_{1}$ and $P_{2}$ (cf. equation 11).

For example, if $\mathrm{y}=1974$, then the two defined periods are [1959-1973] and [1974-2012].

${ }^{*} p<0.10,{ }^{* *} p<0.05,{ }^{* * *} p<0.01$

Detailed results are given in Appendix D.

The model with no breaks is rejected only for a few years in the mid-1970s. More precisely, 1975 is the year where the null hypothesis is the most strongly rejected (see Table 5 and Appendix D for detailed results). The estimations indicate that the long-run elasticity decreases from 0.22 in the first period (1959$1974)$ to 0.18 in the second period (1975-2012).

Two complementary explanations can be offered to understand why this break leads to a persistent decline in the impact of agricultural research. On the research side, the beginning of the 1970s is 20 years after the first post-World War II agricultural research investments that targeted increased agricultural productivity to feed the French and European populations. These investments made during the period 1945-55 lead to radical innovations at the end of the 1960s and beginning of the 1970s, as illustrated by Cornu et al. (2018). In contrast, the research conducted later may have led to more incremental innovations as the agricultural sector became more mature. In summary, 25 years after the war, the results of the initial research. investment matured, and the impact of research declined thereafter. The second explanation is the oil shock that negatively and substantially affected the productivity of industrialized countries.

Even if we observe a slight decline for some years, it is important to underline the robustness of our estimated elasticity since there is no significant difference between the two sub-periods for a large set of years (from 1978 to 2007). 


\subsection{Alternative construction of the stock of knowledge}

Hypotheses 2 and 3 aim to capture two important stylized facts in the history of agricultural research since the 80s: public agricultural research has moved to more fundamental objectives, leading possibly to longer lags, and research priorities have become more diversified with stronger weight placed on environment and nutrition issues.

With Hypothesis 2, we analyse whether the impact of the most recent research investments on the stock of knowledge are delayed. In other words, the more recent stocks of knowledge are based on older investments compared to the oldest stocks. More specifically, we assume that the peak of the research lag moves progressively from either 10 or 15 years towards 25 years. ${ }^{23}$ The non-significant $\mathrm{F}$ statistics for models 2 and 2' and models 3 and 3' (see Table $6)$ indicate the absence of any long-run relationship. The model with increasing lags is inconclusive, so Hypothesis 2 cannot be confirmed. One possible explanation is that the tools for producing and diffusing knowledge have become more efficient simultaneously, leading to shorter delays between research investment and the direct outcome of the research. One complementary explanation relates to the increasing efficiency of the industrial sector in bringing innovations to market.

In Hypothesis 3, we try to better take into account the diversification of research priorities towards environmental, food safety and nutritional issues that do not have direct impacts on agricultural TFP. The results are presented in table 7. Regardless of the method that we use to capture the share of total research investment dedicated to improving agricultural productivity, the qualities of the estimations are equivalent to those that we get in models 1 and 1 '. The long-run elasticity is (slightly) greater if we remove investments related to nutritional issues (models 4 and 4') and slightly more if we also remove the investments related to environmental issues (models 5 and 5 '). The economic impact indicators are also slightly greater; IRR increases by 1 to 2 points, MIRR increases by less than 1 point, and $\mathrm{BC}$ increases by 5 to 8 units.

These results are in line with Hypothesis 3, but the differences are very small. On possible explanation for this small difference is that nutrition and environment issues had been lower priorities for a long period of time. These issues became more important rather recently (see Figure 4) and, because of the rather long research lag, the effect on the estimate for the whole period is quite small.

\footnotetext{
${ }^{23}$ Hence, the stock of knowledge for the first years of the investigation (from 1959 on) is based on lags that are, on average, shorter compared to the stock of knowledge for the last years.
} 
Table 6: Estimated results of models with increasing lags

\begin{tabular}{|c|c|c|c|c|}
\hline & $\begin{array}{l}\text { Model 2 } \\
(\alpha=0)\end{array}$ & $\begin{array}{l}\text { Model 2' } \\
(\alpha=0.25)\end{array}$ & $\begin{array}{l}\text { Model 3 } \\
(\alpha=0)\end{array}$ & $\begin{array}{l}\text { Model 3' } \\
(\alpha=0.25)\end{array}$ \\
\hline \multicolumn{5}{|l|}{ ARDL } \\
\hline L.lnTFP & $\begin{array}{c}0.401^{* * *} \\
(0.115)\end{array}$ & $\begin{array}{c}0.399^{* * *} \\
(0.115)\end{array}$ & $\begin{array}{c}0.368^{* * *} \\
(0.116)\end{array}$ & $\begin{array}{c}0.366^{* * *} \\
(0.116)\end{array}$ \\
\hline L2.lnTFP & $\begin{array}{c}0.474^{* * *} \\
(0.112)\end{array}$ & $\begin{array}{c}0.472^{* * *} \\
(0.112)\end{array}$ & $\begin{array}{c}0.456^{* * *} \\
(0.111)\end{array}$ & $\begin{array}{c}0.453^{* * *} \\
(0.111)\end{array}$ \\
\hline $\ln K$ & $\begin{array}{l}0.024^{*} \\
(0.013)\end{array}$ & $\begin{array}{l}0.023^{*} \\
(0.012)\end{array}$ & $\begin{array}{l}0.031^{* *} \\
(0.014)\end{array}$ & $\begin{array}{l}0.030^{* *} \\
(0.013)\end{array}$ \\
\hline lnDif_R_ETP & $\begin{array}{l}0.008^{* *} \\
(0.004)\end{array}$ & $\begin{array}{l}0.008^{* *} \\
(0.004)\end{array}$ & $\begin{array}{l}0.008^{* *} \\
(0.004)\end{array}$ & $\begin{array}{l}0.008^{* *} \\
(0.003)\end{array}$ \\
\hline _cons & $\begin{array}{l}0.505^{* *} \\
(0.225) \\
\end{array}$ & $\begin{array}{c}0.480^{* *} \\
(0.211)\end{array}$ & $\begin{array}{l}0.738^{* *} \\
(0.289) \\
\end{array}$ & $\begin{array}{c}0.709^{* * *} \\
(0.274)\end{array}$ \\
\hline $\begin{array}{l}\mathbf{E C M} \\
\operatorname{adj}\end{array}$ & $\begin{array}{c}-0.125^{* *} \\
(0.057)\end{array}$ & $\begin{array}{c}-0.128^{* *} \\
(0.058)\end{array}$ & $\begin{array}{c}-0.176^{* *} \\
(0.069)\end{array}$ & $\begin{array}{c}-0.181^{* *} \\
(0.071)\end{array}$ \\
\hline LD.lnTFP & $\begin{array}{c}-0.474^{* * *} \\
(0.112)\end{array}$ & $\begin{array}{c}-0.472^{* * *} \\
(0.112)\end{array}$ & $\begin{array}{c}-0.456^{* * *} \\
(0.111)\end{array}$ & $\begin{array}{c}-0.453^{* * *} \\
(0.111)\end{array}$ \\
\hline D. $\ln K$ & $\begin{array}{l}0.024^{*} \\
(0.013)\end{array}$ & $\begin{array}{l}0.023^{*} \\
(0.012)\end{array}$ & $\begin{array}{l}0.031^{* *} \\
(0.014)\end{array}$ & $\begin{array}{l}0.030^{* *} \\
(0.013)\end{array}$ \\
\hline D.lnDif_R_ETP & $\begin{array}{c}0.008^{* *} \\
(0.004)\end{array}$ & $\begin{array}{c}0.008^{* *} \\
(0.004)\end{array}$ & $\begin{array}{l}0.008^{* *} \\
(0.004)\end{array}$ & $\begin{array}{c}0.008^{* *} \\
(0.003)\end{array}$ \\
\hline $\begin{array}{l}\text { ECM_LR } \\
\ln K\end{array}$ & $\begin{array}{c}0.192^{* * *} \\
(0.032)\end{array}$ & $\begin{array}{c}0.180^{* * *} \\
(0.029)\end{array}$ & $\begin{array}{c}0.178^{* * *} \\
(0.019)\end{array}$ & $\begin{array}{c}0.167^{* * *} \\
(0.018)\end{array}$ \\
\hline lnDif_R_ETP & $\begin{array}{l}0.065^{*} \\
(0.038)\end{array}$ & $\begin{array}{l}0.063^{*} \\
(0.036)\end{array}$ & $\begin{array}{l}0.046^{*} \\
(0.025)\end{array}$ & $\begin{array}{l}0.045^{*} \\
(0.024)\end{array}$ \\
\hline _cons & $\begin{array}{c}4.042^{* * *} \\
(0.187)\end{array}$ & $\begin{array}{c}3.739^{* * *} \\
(0.220)\end{array}$ & $\begin{array}{c}4.194^{* * *} \\
(0.117)\end{array}$ & $\begin{array}{c}3.914^{* * *} \\
(0.134)\end{array}$ \\
\hline Observations & 51 & 51 & 51 & 51 \\
\hline ARDL R-squared & 0.988 & 0.988 & 0.989 & 0.989 \\
\hline ECM R-squared & 0.393 & 0.394 & 0.412 & 0.413 \\
\hline F-statistic & 4.883 & 4.968 & 6.429 & 6.521 \\
\hline
\end{tabular}

Standard errors in parentheses.

Dif_R_ETP : Difference between Rainfall and Evapotranspiration.

${ }^{*} p<0.10,{ }^{* *} p<0.05,{ }^{* * *} p<0.01$ 
Table 7: Estimated results of models considering the evolution of fields of research

\begin{tabular}{|c|c|c|c|c|}
\hline & $\begin{array}{c}\text { Model } 4 \\
(\alpha=0)\end{array}$ & $\begin{array}{l}\text { Model 4' } \\
(\alpha=0.25)\end{array}$ & $\begin{array}{c}\text { Model } 5 \\
(\alpha=0)\end{array}$ & $\begin{array}{l}\text { Model 5' } \\
(\alpha=0.25)\end{array}$ \\
\hline $\begin{array}{l}\text { ARDL } \\
\text { L.lnTFP }\end{array}$ & $\begin{array}{l}0.234^{*} \\
(0.124)\end{array}$ & $\begin{array}{l}0.230^{*} \\
(0.124)\end{array}$ & $\begin{array}{l}0.239^{*} \\
(0.123)\end{array}$ & $\begin{array}{l}0.234^{*} \\
(0.123)\end{array}$ \\
\hline $\mathrm{L} 2 . \operatorname{lnTFP}$ & $\begin{array}{c}0.380^{* * *} \\
(0.110)\end{array}$ & $\begin{array}{c}0.373^{* * *} \\
(0.111)\end{array}$ & $\begin{array}{c}0.385^{* * *} \\
(0.110)\end{array}$ & $\begin{array}{c}0.378^{* * *} \\
(0.110)\end{array}$ \\
\hline $\ln K$ & $\begin{array}{c}0.061^{* * *} \\
(0.019)\end{array}$ & $\begin{array}{c}0.058^{* * *} \\
(0.018)\end{array}$ & $\begin{array}{c}0.060^{* * *} \\
(0.018)\end{array}$ & $\begin{array}{c}0.057^{* * *} \\
(0.017)\end{array}$ \\
\hline lnDif_R_ETP & $\begin{array}{c}0.007^{* *} \\
(0.003)\end{array}$ & $\begin{array}{c}0.007^{* *} \\
(0.003)\end{array}$ & $\begin{array}{l}0.007^{* *} \\
(0.003)\end{array}$ & $\begin{array}{l}0.007^{* *} \\
(0.003)\end{array}$ \\
\hline _cons & $\begin{array}{c}1.716^{* * *} \\
(0.495) \\
\end{array}$ & $\begin{array}{c}1.665^{* * *} \\
(0.475) \\
\end{array}$ & $\begin{array}{c}1.680^{* * *} \\
(0.487) \\
\end{array}$ & $\begin{array}{c}1.632^{* * *} \\
(0.468) \\
\end{array}$ \\
\hline $\begin{array}{l}\mathbf{E C M} \\
\text { adj }\end{array}$ & $\begin{array}{c}-0.386^{* * *} \\
(0.112)\end{array}$ & $\begin{array}{c}-0.396^{* * *} \\
(0.114)\end{array}$ & $\begin{array}{c}-0.377^{* * *} \\
(0.109)\end{array}$ & $\begin{array}{c}-0.388^{* * *} \\
(0.111)\end{array}$ \\
\hline LD.lnTFP & $\begin{array}{c}-0.380^{* * *} \\
(0.110)\end{array}$ & $\begin{array}{c}-0.373^{* * *} \\
(0.111)\end{array}$ & $\begin{array}{c}-0.385^{* * *} \\
(0.110)\end{array}$ & $\begin{array}{c}-0.378^{* * *} \\
(0.110)\end{array}$ \\
\hline D.lnK & $\begin{array}{c}0.061^{* * *} \\
(0.019)\end{array}$ & $\begin{array}{c}0.058^{* * *} \\
(0.018)\end{array}$ & $\begin{array}{c}0.060^{* * *} \\
(0.018)\end{array}$ & $\begin{array}{c}0.057^{* * *} \\
(0.017)\end{array}$ \\
\hline D.lnDif_R_ETP & $\begin{array}{l}0.007^{* *} \\
(0.003) \\
\end{array}$ & $\begin{array}{l}0.007^{* *} \\
(0.003) \\
\end{array}$ & $\begin{array}{l}0.007^{* *} \\
(0.003)\end{array}$ & $\begin{array}{c}0.007^{* *} \\
(0.003)\end{array}$ \\
\hline $\begin{array}{l}\text { ECM_LR } \\
\ln K\end{array}$ & $\begin{array}{c}0.158^{* * *} \\
(0.007)\end{array}$ & $\begin{array}{c}0.147^{* * *} \\
(0.006)\end{array}$ & $\begin{array}{c}0.159^{* * *} \\
(0.007)\end{array}$ & $\begin{array}{c}0.148^{* * *} \\
(0.006)\end{array}$ \\
\hline lnDif_R_ETP & $\begin{array}{l}0.019^{*} \\
(0.010)\end{array}$ & $\begin{array}{l}0.018^{*} \\
(0.010)\end{array}$ & $\begin{array}{l}0.019^{*} \\
(0.010)\end{array}$ & $\begin{array}{l}0.019^{*} \\
(0.010)\end{array}$ \\
\hline _cons & $\begin{array}{c}4.445^{* * *} \\
(0.043)\end{array}$ & $\begin{array}{c}4.201^{* * *} \\
(0.048)\end{array}$ & $\begin{array}{c}4.457^{* * *} \\
(0.044)\end{array}$ & $\begin{array}{c}4.211^{* * *} \\
(0.049)\end{array}$ \\
\hline Observations & 51 & 51 & 51 & 51 \\
\hline ARDL R-squared & 0.990 & 0.990 & 0.990 & 0.990 \\
\hline ECM R-squared & 0.470 & 0.472 & 0.469 & 0.471 \\
\hline F-statistic & $11.969 * *$ & $12.184^{* *}$ & $11.864^{* *}$ & $12.09 * *$ \\
\hline IRR & 23.5 & 23 & 24.1 & 23.6 \\
\hline $\mathrm{BC}$ & 33.392 & 31.075 & 36.401 & 33.867 \\
\hline MIRR & 10.535 & 10.377 & 10.726 & 10.567 \\
\hline
\end{tabular}




\section{Conclusion}

To the best of our knowledge, this paper presents the first analysis of the aggregate impact of French public agricultural research on agricultural productivity in France. Our main goal was to compare the results of these estimations with those arising from the literature as summarized in various surveys (Evenson, 2001; Alston, 2010) and recent contributions (Alston, 2010; Sheng et al., 2011). Our results exhibit a very similar pattern of impacts to those obtained for other countries. We find that the stock of knowledge has a positive and significant impact on agricultural productivity in France with an elasticity of approximately 0.15-0.16. The various economic indicators of this impact (an IRR of approximately $23 \%$, an MIRR of $10 \%$, and a BC ratio of 32 ) are close to the recent estimates obtained in the literature. Finally, we show that accounting for foreign public agricultural $R \& D$ expenses is very important to avoid an overestimation of the impact of domestic expenses.

Several complementary analyses are also made in this article. First, we test whether the elasticity varies over time, and we provide evidence of a significant decrease in this elasticity after the mid-1970s. Moreover we do not find evidence of a change in recent years. Second, The reorientation of public research towards more fundamental objectives could suggest a possible increase in the research lag over time, but the econometric analysis does not support this hypothesis. Finally, when we distinguish among agricultural priorities and conduct an analysis on research investments that target productivity enhancement, we show that the estimated impact is slightly greater than when we consider agricultural research as a whole.

The analysis presented in this paper can be improved in several ways. We expect that regular updates of the time series will allow for a better characterization of the evolution of research investment and whether this evolution alters the impact on agricultural research on productivity. More flexible econometric methodologies should be considered to test whether the research lag has changed over time. Given some technical limitations of the Fisher chained index (especially untransitivity issue), it would be useful to extend the analyses by testing other types of indexes, such as the Lowe TFP index proposed by O'Donnell (2012). This extension would enable to test the robustness of our results with respect to the method used for compiling the TFP Index. Additionally, private research investment and a portion of extension expenses are not considered in our analysis, consistently with other works. These investments are now more important than public research investments (Heisey et al., 2010; Fuglie and Toole, 2014), and it is crucial to take them into account to better understand both the impact of private investment and the modification of the estimated impact of public research when private research is taken (or not) into account. Another important perspective is to extend the analysis to the European level, explaining national TFP by research investments made by each country and neighbouring European countries. Spillovers from outside Europe are important and should not be modelled only by US investment. Indeed, the distribution of agricultural research investment worldwide has shifted over the past two decades (Pardey 
et al., 2016). Extending the analysis to the European level would also require analysing the impact of climate conditions on each of the European countries, as in Ortiz-Bobea et al. (2018). Finally, this paper shed light on the evolution of public agricultural research priorities, especially since the 1990s. Our strategy here was to focus on agricultural productivity as an explained variable. Another major avenue would be to analyse the non-economic impact of research (e.g., environmental and health impacts). Such diverse impacts have been characterized in recent case studies (Colinet et al., 2014). One important challenge would be to develop sufficiently general proxies to measure these non-economic impacts for almost any type of agricultural research. 


\section{Appendix}

\section{A Complementary information on the dataset}

\section{A.1 The climatic control variable}

The climatic variables are available from the SAFRAN database and are based on daily records from 1960 to 2012 over an $8 \times 8 \mathrm{~km}$ grid. Only observations under an elevation of $800 \mathrm{~m}$ are considered consistent with the agricultural crop production condition, leading to 7613 observation points. The variables considered are the global radiation, the sum of the rainfall over the year, the sum of the positive temperature (higher than $0^{\circ} \mathrm{C}$ ) and the difference between the annual rainfall and the annual evapotranspiration (measured following the FAO methodology). The variables for a given year were computed using data from January 1st to December 31st. For the difference between the annual rainfall and the annual evapotranspiration, the variable was expressed as the difference with respect to the minimum over the full period. Finally, we compute (and use for the estimations) an index that corresponds to the value of the variable for a given year divided by the average value over the full period (1960-2012).

\section{A.2 Distribution among agricultural research priorities}

Agricultural research is distributed among three main areas: agriculture, food (and consumption) and environment. We present here the proxies that are built to establish the distribution of public research investment in these three areas over the whole time series. We use data on public agricultural research, and in the case of France, public agricultural research is mainly represented by INRA. The proxies are based on raw data from INRA.

\section{- Proxy based on the number of researchers}

INRA is organized into research divisions, and we have fairly good information about the demography in each division since 1946. The analysis is based on the number of researchers per division. The number of research divisions has changed over time: the maximum number was 27 in the 1980s, and the minimum was 13 (current period).

Each research division can be ranked in one of the three following areas: agriculture and environment, food and, finally, general (for example, the social science research division is classified in this "general" area). Distinguishing between agriculture and environment is impossible as quite a number of these divisions cover these two areas. We define $N_{j}^{t}$ as the number of researchers in division $j$ at year $t$, and $\alpha_{j k}$ is a dummy variable that is equal to 1 if division $j$ belongs to area $\mathrm{k}$, where $\mathrm{k}=$ \{agriculture and environment, food, general $\}$.

We can then compute the share of research devoted to agriculture (and 
environment) as follows:

$$
S R_{A g+E n v t}^{t}=\frac{\sum_{j} \alpha_{j A g+E n v t} N_{j}^{t}}{\sum_{j} \alpha_{j A g+E n v t} N_{j}^{t}+\sum_{j} \alpha_{j F o o d} N_{j}^{t}}
$$

This proxy can be computed over the whole period from 1946 to 2013.

\section{- Proxy based on the number of publications}

The analysis is based on the publications of INRA researchers over the period 1981-2013 extracted from the Web of Science (WoS). Publications are counted by subject category, $N_{i}^{t}$ being the number of publications in the WoS subject category (SC) $i$ in period $t$. This approach weights each publication in a given journal by the (inverse of the) number of subject categories to which this journal belongs. For example, a publication in a journal belonging to the subject categories 1 and 3 is counted as 0.5 in each of these two subject categories.

Each subject category is affiliated with agricultural areas using the variable $\alpha_{i k}$. Four main areas are distinguished, namely, agriculture, food (and consumption), environment and general. "General" corresponds to subject categories that either cover the three other areas (e.g., economics) or is out of the scope of the three other areas (e.g., acoustics). $\alpha_{i k}=1$ if the subject category $i$ is in the area $k(k \in\{A g$, Food, Envt, Gen $\})$. Some subject categories are affiliated with both agriculture and food $\left(\alpha_{i A g}=\alpha_{i F o o d}=0.5\right.$ in these cases). The table below synthesizes the number of subject categories and publications per research area.

\begin{tabular}{c|c|c}
\hline Area & No. of SCs & No. of publications \\
\hline Agriculture & 20 & 32126 \\
Food & 43 & 13675 \\
Ag + Food & 30 & 3140 \\
Environment & 21 & 5352 \\
General & 109 & 19685 \\
\hline Total & 223 & 73978 \\
\hline
\end{tabular}

We first compute the number of publications in each research area as follows:

$$
N_{k}^{t}=\sum_{i} \alpha_{i k} \cdot N_{i}^{t}
$$

The share of each of the main agricultural areas (agriculture, food and environment) is then simply defined as follows:

$$
S P_{k}^{t}=\frac{N_{k}^{t}}{N_{A g}^{t}+N_{\text {Food }}^{t}+N_{E n v t}^{t}}
$$




\section{- Synthesis}

It was possible to compare the two proxies $S P_{k}^{t}$ and $S R_{k}^{t}$ over the period 19812013. The difference $S R_{A g+E n v t}^{t}-\left(S P_{A g}^{t}+S P_{E n v t}^{t}\right)$ (in absolute value) is equal to $3.2 \%$ on average with a maximum of $10 \%$ at the end of the $80 \mathrm{~s}$.

As we want to separate the research in the area of agriculture from the research in the areas of food and environment, we use the proxy based on the publication $S P_{A g}^{t}$ during the period 1981-2013.

For the period 1945-1980, we use the proxy based on the number of researchers $S R_{A g+E n v t}^{t}$ weighed by the average share of agriculture research with respect to both agriculture and environment research in the publications over the period 1981-1995 (91.9\%). The balance between agriculture and environment in the publications between 1981 and 1995 was rather stable (see Figure 4). Hence, we assume here that this share was identical between 1945 and 1980.

\section{A.3 Public research investments between 1909 and 1944}

The computation of the knowledge stock for a given year requires having data on the research expenses over the previous 50 years. The oldest stock of knowledge is for year 1959 and is estimated from the research investment from 1909 until 1959. The French public agricultural research investment over the period 19091944 was small, but no precise data are available.

We hence extrapolate our research spending dataset from 1909 until 1944 using the trend of US spending. This assumption has a minor effect because the research spending in 1945 (and in the years before) represents less than $1 \%$ of the spending in the recent years. Alternative assumptions were tested and have minor impacts on the estimations. More precisely, these alternative assumptions were either to consider a stable spending from 1909 to 1944 equal to that in 1945 or to consider a linear trend from 1929 to 1939.

When considering the distribution of priorities over 1909-1944, we suppose that this distribution is stable until 1945. Hence, the share of research devoted to improving agricultural productivity is $77.2 \%$. 


\section{B Computation of the economic impact from the econometric estimates}

To obtain the indicators measuring the economic impact of $\mathrm{R} \& \mathrm{D}$, such as the IRR, it is first necessary to measure the variation in the production level induced by a given variation in the knowledge stock and, second, to use this measure to compute the chosen indicator.

\section{B.1 Impact of a change in the knowledge stock on pro- ductivity and production levels}

$$
\begin{aligned}
\ln T F P_{t} & =\theta_{0}+\theta^{\prime} \ln \left(K_{T O T_{t}}\right)+\nu_{t} \\
& =\theta_{0}+\theta^{\prime}\left[\ln \left(K_{F R_{t}}\right)+\alpha \ln \left(K_{U S_{t}}\right)\right]+\nu_{t}
\end{aligned}
$$

$\alpha$ is set to 0.25 .

$\widehat{\theta}$ is the estimated long-run knowledge coefficient from the following ARDL estimation:

$\Delta \ln \left(T F P_{t}\right)=\mu+\zeta\left[\ln \left(T F P_{t-1}\right)-\theta^{\prime} \ln \left(K_{T O T_{t-1}}\right)\right]-\gamma_{2} \Delta \ln \left(T F P_{t-1}\right)+\beta_{1} \Delta \ln \left(K_{T O T_{t}}\right)+\varepsilon_{t}$

Since we estimate a log-log model, $\widehat{\theta}$ is the long-run elasticity of productivity with respect to Knowledge. Indeed, from (12):

$$
\frac{\partial \ln \left(T F P_{t}\right)}{\partial \ln \left(K_{T O T_{t}}\right)}=\frac{\partial T F P_{t} / T F P_{t}}{\partial K_{T O T_{t}} / K_{T O T_{t}}}=\widehat{\theta}
$$

Considering a change in $\mathrm{R} \& \mathrm{D}$ expenditures (additional investment), we want to measure the change in productivity induced. From (13) we have the following:

$$
\Delta T F P_{t}=\widehat{\theta} \cdot T F P_{t} \cdot \frac{\Delta K_{T O T_{t}}}{K_{T O T_{t}}}
$$

and since

$$
\begin{aligned}
\ln \left(K_{T O T_{t}}\right) & =\ln \left(K_{F R_{t}}\right)+\alpha \ln \left(K_{U S_{t}}\right) \\
e^{\ln \left(K_{T O T_{t}}\right)} & =e^{\ln \left(K_{F R_{t}}\right)+\alpha \ln \left(K_{U S_{t}}\right)}=e^{\ln \left(K_{F R_{t}}\right)} \cdot e^{\alpha \ln \left(K_{U S_{t}}\right)} \\
K_{T O T_{t}} & =K_{F R_{t}} \cdot K_{U S_{t}}^{\alpha} \\
\Delta K_{T O T_{t}} & =K_{T O T_{t}}^{\prime}-K_{T O T_{t}} \\
& =K_{F R_{t}}^{\prime} \cdot K_{U S_{t}}^{\alpha}-K_{F R_{t}} \cdot K_{U S_{t}}^{\alpha} \\
& =K_{U S_{t}}^{\alpha}\left(K_{F R_{t}}^{\prime}-K_{F R_{t}}\right) \\
& =K_{U S_{t}}^{\alpha} \cdot \Delta K_{F R_{t}}
\end{aligned}
$$

with $K_{F R_{t}}^{\prime}$ (resp. $K_{T O T_{t}}^{\prime}$ ) the French (resp. total) knowledge at t induced by an additional investment in $\mathrm{R} \& \mathrm{D}$ expenditures at $T_{0}\left(\Delta I_{T_{0}}\right)$. With our data, we consider $T_{0}=1960$.

Thus, 


$$
\frac{\Delta K_{T O T_{t}}}{K_{T O T_{t}}}=\frac{K_{U S_{t}}^{\alpha} \cdot \Delta K_{F R_{t}}}{K_{F R_{t}} \cdot K_{U S_{t}}^{\alpha}}=\frac{\Delta K_{F R_{t}}}{K_{F R_{t}}}
$$

This is obvious as

$$
\begin{aligned}
\frac{\partial \ln \left(T F P_{t}\right)}{\partial \ln \left(K_{T O T_{t}}\right)} & =\frac{\partial \ln \left(T F P_{t}\right)}{\partial \ln \left(K_{F R_{t}}\right)}=\widehat{\theta} \\
\frac{\partial T F P_{t} / T F P_{t}}{\partial K_{T O T_{t}} / K_{T O T_{t}}} & =\frac{\partial T F P_{t} / T F P_{t}}{\partial K_{F R_{t}} / K_{F R_{t}}}=\widehat{\theta}
\end{aligned}
$$

So

$$
\Delta T F P_{t}=\widehat{\theta} \cdot T F P_{t} \cdot \frac{\Delta K_{F R_{t}}}{K_{F R_{t}}}
$$

Finally, we can compute the change in the production level. Assuming a Cobb-Douglas production function, the level of production (measured by the agricultural added value) is as follows: $Y_{t}=C_{t}^{\alpha} \cdot L_{t}^{\beta} \cdot K_{F R_{t}}^{\gamma}$

Supposing that a change in productivity has few effects on capital and labour leads to the following:

$$
\begin{aligned}
\frac{\Delta Y_{t}}{Y_{t}} & =\frac{\Delta T F P_{t}}{T F P_{t}}=\widehat{\theta} \cdot \frac{\Delta K_{F R_{t}}}{K_{F R_{t}}} \\
\Rightarrow \Delta Y_{t} & =\widehat{\theta} \cdot \frac{\Delta K_{F R_{t}}}{K_{F R_{t}}} \cdot Y_{t}
\end{aligned}
$$

\section{B.2 Computation of economic indicators}

Following Andersen (2015), we define the following three economic indicators:

- Internal Rate of Return (IRR). The IRR is defined as the i that satisfies

$$
\begin{array}{r}
\sum_{t=T_{0}}^{T_{0}+L-1} \frac{\Delta Y_{t}}{(1+i)^{t}}=\Delta I_{T_{0}} \\
\Rightarrow \sum_{t=T_{0}}^{T_{0}+L-1} \widehat{\theta} \cdot \frac{\Delta K_{F R_{t}}}{K_{F R_{t}}} \cdot Y_{t} \cdot \frac{1}{(1+i)^{t}}=\Delta I_{T_{0}}
\end{array}
$$

or in a continuous setting (see Andersen (2015)), the IRR is as follows:

$$
\begin{aligned}
& \sum_{t=T_{0}}^{T_{0}+L-1} \Delta Y_{t} \cdot e^{-i t}=\Delta I_{T_{0}} \\
& \Rightarrow \sum_{t=T_{0}}^{T_{0}+L-1} \widehat{\theta} \cdot \Delta \ln \left(\overline{K_{F R_{t}}}\right) \cdot Y_{t} \cdot e^{-i t}=\Delta I_{T_{0}}
\end{aligned}
$$

with $\Delta \ln \left(\overline{K_{F R_{t}}}\right)=\ln \left(K_{F R_{t}}^{\prime}\right)-\ln \left(K_{F R_{t}}\right)$ 
- Benefit-cost ratio (BC). We first compute the present value of benefits:

$$
P V B=\sum_{t=T_{0}}^{T+L-1} \widehat{\theta} \cdot \Delta \ln \left(\overline{K_{F R_{t}}}\right) \cdot Y_{t} \cdot e^{-r t}
$$

with $r$ being a real interest rate. Following Alston et al. (2011), we consider $\mathrm{r}=3 \%$.

The BC is then defined as follows:

$$
B C=\frac{P V B}{P V C} \quad \text { with } P V C=\Delta I_{T_{0}}
$$

Following Andersen (2015), we consider $\Delta I_{T_{0}}=1000$.

- Modified internal rate of return (MIRR). We first compute the future value of benefits after 50 years as follows:

$$
F V B=e^{r * 50} \cdot P V B
$$

The MIRR is then defined as follows:

$$
M I R R=\left(\frac{F V B}{P V C}\right)^{\frac{1}{N}}-1=\left(\frac{F V B}{\Delta I_{T_{0}}}\right)^{\frac{1}{50}}-1
$$




\section{Weak and Strong exogeneity of the stock of knowledge}

\section{C.1 Weak exogeneity}

Valid inference with respect to estimates of Eq. 8 requires $\ln K_{t}$ to be weakly exogenous with respect to the parameters of interest in the long-run equilibrium relationship. Boswijk and Urbain (1997) show that weak exogeneity of $\ln K_{t}$ with respect to the long-run parameters can be tested by a variable addition test of the error correction term in the marginal model for $\ln K_{t}$, i.e., testing the nullity of $\zeta$ in

$$
\begin{aligned}
\Delta \ln K_{t}= & a_{0}+a_{1} t+\zeta\left[\ln \left(T F P_{t-1}\right)-\theta_{4}^{\prime} \ln \left(K_{t-1}^{T o t}\right)\right]+ \\
& \sum_{i=1}^{p} \psi_{i} \Delta \ln \left(T F P_{t-i}\right)+\sum_{i=1}^{p} \phi_{i} \Delta \ln \left(K_{t-i}^{T o t}\right)+\varepsilon_{t}
\end{aligned}
$$

Typically, the information criteria entail four lags when estimating Eq. 15. The parameter estimates are reported in Table 8. The usual significance test indicates that the null hypothesis, $\mathrm{H}_{O}: \zeta=0$, cannot be rejected (term ECT1.lag is non-significant), indicating that $\ln \left(K_{t}^{\text {Tot }}\right)$ is weakly exogenous.

Table 8: ECM testing weak exogeneity of $l n_{K}^{T o t}$

\begin{tabular}{lrr}
\hline & Model 1 & \\
\hline (Intercept) & 0.000 & $(0.000)$ \\
ECT1.lag & -0.002 & $(0.002)$ \\
LD.lnK & $3.095^{* * *}$ & $(0.151)$ \\
L2D.lnK & $-3.396^{* * *}$ & $(0.441)$ \\
L3D.lnK & $1.490^{* * *}$ & $(0.440)$ \\
L4D.lnK & -0.191 & $(0.150)$ \\
LD.lnTFP & $0.003^{*}$ & $(0.002)$ \\
L2D.nTFP & $0.004^{* *}$ & $(0.001)$ \\
L3D.lnTFP & $0.003^{* *}$ & $(0.001)$ \\
L4D.lnTFP & 0.001 & $(0.001)$ \\
\hline Num. obs. & 49 & \\
\hline
\end{tabular}

Standard errors are given in parentheses.

${ }^{* * *} p<0.01,{ }^{* *} p<0.05,{ }^{*} p<0.1$

$\mathbf{L}$ and $\mathbf{D}$ are the standard time series operators (resp. lag and difference). 


\section{C.2 Strong exogeneity}

'Granger non-causality' has been shown to be equivalent to strong exogeneity (Pagan and Wickens, 1989). Vector autoregression (VAR) or the errorcorrection model (ECM) can be used to examine the Granger causality among variables. Thus, one could conduct a VAR in first-order differences of the variables if the variables were known to be I(1) (integrated of order one) with no cointegration, and one could conduct an ECM if the variables were known as to be cointegrated. Hence, whether the variables are integrated, cointegrated, or (trend) stationary is usually pre-tested. Toda and Yamamoto (1995) showed that causality inference in ECM may suffer from severe pre-test biases. Indeed, pre-tests for cointegration ranks in Johansen-type ECM are very sensitive to the values of the nuisance parameters in finite samples. Hence if the system contains unit roots, standard Wald statistics based on ordinary least-squares (OLS) estimation of a level VAR model for testing coefficient restrictions have non-standard asymptotic distributions that may involve nuisance parameters (see, e.g., Sims et al. (1990), and Toda and Phillips (1993)).

We first study the level of integration of the variables, $\ln T F P_{t}$ and $\ln K_{t}^{T o t}$. These series are plotted in Figure 5, and unit root tests are reported in Table 9. $\ln T F P_{t}$ appears to be stationary after one accounts for a break in the intercept. Indeed, according to the Zivot and Andrews (1992) test, a break in the intercept occurs in 1981 and the non-stationarity null hypothesis is rejected at the usual $1 \%$ significance level. Regarding the $\ln K_{t}^{\text {Tot }}$ series, note that it is built as a stationary variable around a nonlinear trend. Interestingly enough, when accounting for a break in the trend using the Zivot and Andrews test, this variable appears to be stationary at the $1 \%$ level. Note further that both variables appear to be non-stationary when using standard tests that do not allow for breaks.
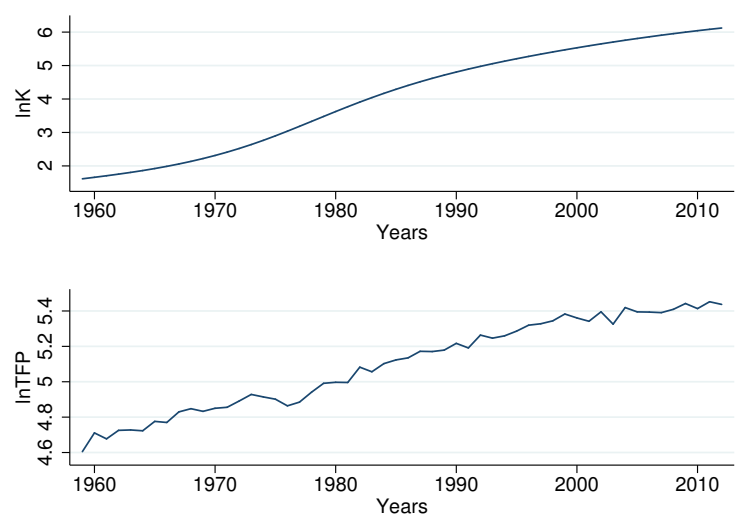

Figure 5: Overall productivity of French agriculture and stock of knowledge series in logarithms $\left(\ln T F P_{t}\right.$ and $\left.\ln K_{t}^{T o t}\right)$ 
Table 9: Unit root tests

\begin{tabular}{lcccc}
\hline Variable & DC & KPSS & \multicolumn{2}{c}{$Z A$} \\
& & & ZA Statistic & Potential break \\
\hline $\ln T F P_{t}$ & $\mathrm{c}$ & $1.444^{* * *}$ & $-5.475^{* * *}$ & 1981 \\
$\ln T F P_{t}$ & $\mathrm{t}$ & $0.206^{* *}$ & $-5.895^{* * *}$ & 1999 \\
& & & & 1974 \\
$\ln K_{t}^{T o t}$ & $\mathrm{c}$ & $1.433^{* * *}$ & -2.591 & 1982 \\
$\ln K_{t}^{T o t}$ & $\mathrm{t}$ & $0.282^{* * *}$ & $-11.749^{* * *}$ & \\
\hline Statistics of each test are reported. & \\
*** denotes rejection of the null hypothesis at the $1 \%$ level, ${ }^{* *}$ at $5 \%$ level. \\
DC: Deterministic Component, c is a constant, t is a linear time trend. \\
KPSS: Kwiatkowski-Philips-Schmidt-Shin test $\left(H_{0}\right.$ stationarity). \\
$Z A:$ Zivot and Andrews test $\left(H_{0}\right.$ non stationarity).
\end{tabular}

Given the above results, we can apply the classical Granger non-causality test. We present the results in Table 10 by adopting a VAR of order 2, which is the same order we adopted in the main econometric analysis conducted in the paper. The results indicate that the null hypothesis that $\ln K_{t}^{\text {Tot }}$ does not Granger-cause $\ln T F P_{t}$ is rejected, and alternatively, the null hypothesis that $\ln T F P_{t}$ does not Granger-cause $\ln K_{t}^{T o t}$ cannot be rejected. ${ }^{24}$ However, unreported results indicate that the Granger non-causality test is very sensitive to the lag order of the VAR. In summary, we provide clear evidence that $\ln K_{t}^{T o t}$ is weakly exogenous, thus allowing us to conduct valid inference, while less robust results were found when testing strong exogeneity.

Table 10: Granger causality Wald tests

\begin{tabular}{cccc}
\hline Null hypothesis & $F$ & $d f$ & $p$ \\
& & & \\
\hline $\ln K_{t}^{\text {Tot }}$ does not Granger-cause $\ln T F P_{t}$ & 3.46 & 2 & 0.04 \\
$\ln T F P_{t}$ does not Granger-cause $\ln K_{t}^{\text {Tot }}$ & 0.67 & 2 & 0.52 \\
\hline
\end{tabular}

${ }^{24}$ Here, the results concern the $\alpha=0$ case, but the same results are obtained with $\alpha=0.25$. 


\section{Estimates of models 1 and 1' with two sub- periods}

Table 11 below provides the same estimate and equality test as table 5 but for all possible sub-periods.

Table 11: Estimated LR elasticities from models 1 and 1' considering two subperiods and test of equality

\begin{tabular}{|c|c|c|c|c|c|c|}
\hline \multirow{3}{*}{$\begin{array}{l}\text { Year }(y) \text { defining } \\
\text { the two sub-periods }\end{array}$} & \multicolumn{6}{|c|}{$\alpha=25($ peak 25$)$} \\
\hline & \multicolumn{6}{|c|}{ LR elasticity and F statistic } \\
\hline & $\widehat{\theta}^{P_{1}}$ & $\widehat{\theta}^{P_{2}}$ & $\mathrm{~F}$ & $\widehat{\theta}^{P_{1}}$ & $\widehat{\theta}^{P_{2}}$ & $\mathrm{~F}$ \\
\hline 1965 & 0.128 & 0.153 & 1.39 & 0.131 & 0.143 & 1.22 \\
\hline 1966 & 0.140 & 0.154 & 0.54 & 0.137 & 0.144 & 0.45 \\
\hline 1967 & 0.137 & 0.153 & 0.68 & 0.135 & 0.143 & 0.59 \\
\hline 1968 & 0.157 & 0.157 & 0.00 & 0.146 & 0.146 & 0.00 \\
\hline 1969 & 0.175 & 0.161 & 0.63 & 0.157 & 0.150 & 0.61 \\
\hline 1970 & 0.169 & 0.160 & 0.27 & 0.154 & 0.149 & 0.28 \\
\hline 1971 & 0.170 & 0.161 & 0.28 & 0.154 & 0.150 & 0.30 \\
\hline 1972 & 0.176 & 0.163 & 0.71 & 0.159 & 0.152 & 0.71 \\
\hline 1973 & 0.191 & 0.169 & $3.19^{*}$ & 0.169 & 0.157 & $3.01^{*}$ \\
\hline 1974 & 0.215 & 0.178 & $21.51^{* * *}$ & 0.185 & 0.166 & $19.77^{* * *}$ \\
\hline 1975 & 0.218 & 0.181 & $36.22^{* * *}$ & 0.190 & 0.169 & $35.99^{* * *}$ \\
\hline 1976 & 0.209 & 0.178 & $14.42^{* * *}$ & 0.186 & 0.168 & $19.46^{* * *}$ \\
\hline 1977 & 0.195 & 0.172 & 2.59 & 0.180 & 0.164 & $5.37^{* *}$ \\
\hline 1978 & 0.096 & 0.132 & 0.69 & 0.102 & 0.122 & 0.56 \\
\hline 1979 & 0.138 & 0.149 & 0.39 & 0.132 & 0.139 & 0.32 \\
\hline 1980 & 0.159 & 0.158 & 0.01 & 0.148 & 0.147 & 0.02 \\
\hline 1981 & 0.153 & 0.155 & 0.03 & 0.143 & 0.145 & 0.03 \\
\hline 1982 & 0.136 & 0.148 & 1.45 & 0.128 & 0.136 & 1.44 \\
\hline 1983 & 0.154 & 0.156 & 0.03 & 0.143 & 0.145 & 0.03 \\
\hline 1984 & 0.149 & 0.154 & 0.26 & 0.139 & 0.142 & 0.29 \\
\hline 1985 & 0.148 & 0.154 & 0.38 & 0.138 & 0.142 & 0.43 \\
\hline 1986 & 0.152 & 0.155 & 0.11 & 0.142 & 0.144 & 0.13 \\
\hline 1987 & 0.150 & 0.154 & 0.31 & 0.140 & 0.143 & 0.34 \\
\hline 1988 & 0.153 & 0.155 & 0.11 & 0.142 & 0.144 & 0.13 \\
\hline 1989 & 0.151 & 0.155 & 0.40 & 0.140 & 0.143 & 0.43 \\
\hline 1990 & 0.149 & 0.154 & 0.95 & 0.138 & 0.142 & 1.00 \\
\hline 1991 & 0.152 & 0.155 & 0.29 & 0.142 & 0.144 & 0.30 \\
\hline 1992 & 0.148 & 0.154 & 1.88 & 0.138 & 0.142 & 1.95 \\
\hline 1993 & 0.152 & 0.156 & 0.54 & 0.141 & 0.144 & 0.56 \\
\hline 1994 & 0.151 & 0.156 & 0.73 & 0.141 & 0.144 & 0.75 \\
\hline 1995 & 0.149 & 0.156 & 1.87 & 0.139 & 0.144 & 1.92 \\
\hline 1996 & 0.151 & 0.156 & 1.21 & 0.141 & 0.144 & 1.24 \\
\hline 1997 & 0.155 & 0.157 & 0.15 & 0.144 & 0.145 & 0.15 \\
\hline 1998 & 0.156 & 0.157 & 0.01 & 0.145 & 0.146 & 0.01 \\
\hline 1999 & 0.157 & 0.157 & 0.00 & 0.146 & 0.146 & 0.00 \\
\hline 2000 & 0.160 & 0.156 & 0.32 & 0.149 & 0.146 & 0.35 \\
\hline 2001 & 0.159 & 0.156 & 0.19 & 0.148 & 0.146 & 0.21 \\
\hline 2002 & 0.156 & 0.157 & 0.06 & 0.145 & 0.146 & 0.05 \\
\hline 2003 & 0.157 & 0.157 & 0.03 & 0.147 & 0.146 & 0.04 \\
\hline 2004 & 0.155 & 0.157 & 0.29 & 0.144 & 0.146 & 0.27 \\
\hline 2005 & 0.157 & 0.156 & 0.02 & 0.146 & 0.146 & 0.02 \\
\hline 2006 & 0.158 & 0.156 & 0.12 & 0.147 & 0.145 & 0.13 \\
\hline 2007 & 0.156 & 0.157 & 0.01 & 0.146 & 0.146 & 0.01 \\
\hline
\end{tabular}




\section{References}

Alphandery, P., Bitoun, P., Dupont, Y., Foulhouze, I. and Harel, M. (1989). L'Etat, la societe de croissance et la politique agricole en France. INRA Paris. Tech. rep., INRA, Paris.

Alston, J. M. (2010). The Benefits from Agricultural Research and Development, Innovation, and Productivity Growth. OECD Food, Agriculture and Fisheries Papers, Organisation for Economic Co-operation and Development, Paris, http://www . oecd-ilibrary . org/content/workingpaper/5km91nfsnkwg-en.

Alston, J. M., Andersen, M. A., James, J. S. and Pardey, P. G. (2010). Persistence Pays. New York, NY: Springer New York, http://link.springer.com/ 10.1007/978-1-4419-0658-8.

Alston, J. M., Andersen, M. A., James, J. S. and Pardey, P. G. (2011). The economic returns to U.S. public agricultural research. American Journal of Agricultural Economics 93: 1257-1277, doi:10.1093/ajae/aar044.

Alston, J. M., Chan-Kang, C., Marra, M. C., Pardey, P. G. and Wyatt, T. J. (2000). A Meta-Analysis of Rates of Return to Agricultural R\&D: Ex Pede Herculem? Research Report 113, IFPRI.

Andersen, M. A. (2015). Public investment in U.S. agricultural R\&D and the economic benefits. Food Policy 51: 38-43, doi:10.1016/j.foodpol.2014.12.005, http://www.sciencedirect.com/science/article/pii/S0306919214002103.

Balcombe, K., Bailey, A. and Iain, F. (2005). Measuring the impact of r\&d on productivity from a econometric time series perspective. Journal of Productivity Analysis 24: 49-72.

Ball, E., Schimmelpfennig, D. and Wang, S. L. (2013). Is U.S. agricultural productivity growth slowing? Applied Economic Perspectives and Policy 35: 435-450, doi:10.1093/aepp/ppt014, http://aepp.oxfordjournals.org/ content/35/3/435.

Ball, V. E., Barkaoui, A., Bureau, J.-C. and Butault, J.-P. (1997). Aggregation methods for intercountry comparisons of prices and real values in agriculture: A review and synthesis *. European Review of Agricultural Economics 24: 183-206, doi:10.1093/erae/24.2.183.

Boswijk, H. P. and Urbain, J.-P. (1997). Lagrance-multiplier tersts for weak exogeneity: a synthesis. Econometric Reviews 16: 21-38.

Brisson, N., Gate, P., Gouache, D., Charmet, G., Oury, F.-X. and Huard, F. (2010). Why are wheat yields stagnating in Europe? A comprehensive data analysis for France. Field Crops Research 119: 201-212, doi:10. 1016/j.fcr.2010.07.012, http://www.sciencedirect.com/science/article/pii/ S0378429010001929. 
Butault, J. and Réquillart, V. (2012). L'agriculture et l'agroalimentaire français à la recherche d'une compétitivité perdue. INRA Sciences Sociales N4-N5: 1-4, https://ageconsearch. umn. edu/record/140204.

Butault, J.-P., Lemarié, S., Musolesi, A., Huard, F., Simioni, M. and Schmitt, B. (2015). L'impact de la recherche agronomique sur la productivité agricole française. une approche par le taux de rentabilité interne (tri) des dépenses publiques affectées à la recherche agronomique en france. INRA Sciences Sociales : $1-5$.

Colinet, L., Joly, P.-B., Gaunand, A., Matt, M., Laredo, P. and Lemarié, S. (2014). ASIRPA-Analyse des Impacts de la Recherche Publique Agronomique. Rapport final. Rapport préparé pour l'Inra. Paris, France. Tech. rep., INRA.

Cornu, P., Valceschini, E. and Maeght-Bournay, O. (2018). L'histoire de l'Inra, entre science et politique. Versailles: Quae Editions.

Diewert, W. (1993). The early history of price index research. In Diewert, W. and Nakamura, A. (eds), Essays in Index Number Theory. Amsterdam: Elsevier Science Limited, 1, 33-65.

Diewert, W. E. and Fox, K. J. (2017). Decomposing productivity indexes into explanatory factors. European Journal of Operational Research 256: 275-291, doi:10.1016/j.ejor.2016.05.04.

Doraszelski, U. and Jaumandreu, J. (2013). R\&d and productivity: Estimating endogenous productivity. The Review of Economic Studies 80: 1338-1383.

Evenson, R. E. (2001). Economic impacts of agricultural research and extension. In Gardner, B. and Rausser, G. (eds), Handbook of Agricultural Economics, Volume 1A. Amsterdam: Elsevier, 573-628.

Fuglie, K. O. and Toole, A. A. (2014). The Evolving Institutional Structure of Public and Private Agricultural Research. American Journal of Agricultural Economics 96: 862-883, doi:10.1093/ajae/aat107, http://ajae. oxfordjournals.org/cgi/doi/10.1093/ajae/aat107.

Gordon, R. J. (2012). Is U.S. Economic Growth Over? Faltering Innovation Confronts the Six Headwinds. Working Paper 18315, National Bureau of Economic Research, http://www.nber.org/papers/w18315.

Griliches, Z. (1958). Research costs and social returns: hybrid corn and related innovations. Journal of Political Economy 66: 419-431.

Griliches, Z. (1998). Patent statistics as economic indicators: a survey. In $R \mathscr{E} D$ and productivity: the econometric evidence. University of Chicago Press, 287343. 
Heisey, P., King, J., Rubenstein, K. D., Bucks, D. and Welsh, R. (2010). Assessing the benefits of public research within an economic framework: the case of USDA's Agricultural Research Service. Tech. Rep. ERR-95, USDA-ERS, https://ageconsearch.umn. edu/record/94852/files/ERR95.pdf.

Hendry, D. F. (2004). Causality and exogeneity in non-stationary economic time series. New Directions in Macromodelling (Contributions to Economic Analysis). Emerald Group Publishing Limited 269: 21-48.

Hendry, D. F. (2017). Granger causality. European Journal of Pure and Applied Mathematics 10: 12-29.

Huffman, W. E. and Just, R. E. (1999). The organization of agricultural research in western developed countries. Agricultural Economics 21: 1-18, doi:10.1016/S0169-5150(99)00014-6, http://www. sciencedirect.com/science/ article/pii/S0169515099000146.

Hurley, T. M., Rao, X. and Pardey, P. G. (2014). Re-examining the Reported Rates of Return to Food and Agricultural Research and Development. American Journal of Agricultural Economics 96: 1492-1504, doi: 10.1093/ajae/aau047, http://ajae.oxfordjournals.org/content/96/5/1492.

James, J. S., Alston, J. M., Pardey, P. G. and Andersen, M. A. (2009). Structural changes in us agricultural production and productivity. Choices: The Magazine of Food, Farm, and Resource Issues 24: 1-5.

Khan, F., Salim, R., Bloch, H. and Islam, N. (2017). The public r\&d and productivity growth in australia's broadacre agriculture: is there a link? Australian Journal of Agricultural and Resource Economics 61: 285-303, doi: 10.1111/1467-8489.12202.

Kripfganz, S. and Schneider, D. C. (2016). ardl: Stata module to estimate autoregressive distributed lag models. 2016 stata conference, chicago, Stata Users Group.

Lechner, M. (2010). The relation of different concepts of causality used in time series and microeconometrics. Econometric Reviews 30: 109-127, doi: 10.1080/07474938.2011.520571.

Levinsohn, J. and Petrin, A. (2003). Estimating production functions using inputs to control for unobservables. The Review of Economic Studies 70: 317341.

Marasas, C., Smale, M. and Singh, R. (2003). The economic impact of productivity maintenance research: breeding for leaf rust resistance in modern wheat. Agricultural Economics 29: 253-263, doi:10.1111/j.1574-0862.2003.tb00162. $\mathrm{x}$, http://onlinelibrary.wiley.com/doi/10.1111/j.1574-0862.2003.tb00162. $\mathrm{x} /$ abstract. 
Mizon, G. and Hendry, D. (1998). Exogeneity, causality, and co-breaking in economic policy analysis of a small econometric model of money in the uk. Empirical Economics 23: 267-294.

Narayan, P. K. (2005). The saving and investment nexus for china: evidence from cointegration tests. Applied Economics 37: 1979-1990.

O'Donnell, C. J. (2012). Nonparametric Estimates of the Components of Productivity and Profitability Change in U.S. Agriculture. American Journal of Agricultural Economics 94: 873-890, doi:10.1093/ajae/aas023.

Olley, G. S. and Pakes, A. (1996). The dynamics of productivity in the telecommunications equipment industry. Econometrica 64: 1263-97.

Ortiz-Bobea, A., Knippenberg, E. and Chambers, R. G. (2018). Growing climatic sensitivity of US agriculture linked to technological change and regional specialization. Science advances 4: eaat4343.

Pagan, A. and Wickens, M. (1989). A survey of some recent econometric methods. Economic Journal 99: 962-1025.

Pardey, P. G., Chan-Kang, C., Dehmer, S. P. and Beddow, J. M. (2016). Agricultural R\&D is on the move. Nature 537: 301-303, doi:10.1038/537301a, http://www . nature.com/doifinder/10.1038/537301a.

Pesaran, M. H. and Shin, Y. (1999). An autoregressive distributed-lag modelling approach to cointegration analysis. In Strom, S. (ed.), Econometrics and Economic Theory in the 20th Century: The Ragnar Frisch Centennial Symposium. Cambridge: Cambridge University Press, 371-413.

Pesaran, M. H., Shin, Y. and Smith, R. J. (2001). Bounds testing approaches to the analysis of level relationships. Journal of Applied Econometrics 16: 289-326, doi:10.1002/jae.616, http://onlinelibrary.wiley.com/doi/10.1002/ jae.616/abstract.

Rouvinen, P. (2002). R\&d-productivity dynamics: Causality, lags, and 'dry holes'. Journal of Applied Economics 5: 123-156, doi:10.1080/15140326.2002. 12040573 .

Sheng, Y., Gray, E. M., Mullen, J. D. and Davidson, A. (2011). Public investment in agricultural $R \& D$ and extension: an analysis of the static and dynamic effects on Australian broadacre productivity. Tech. Rep. 11.7, Grains Research and Development Corporation, http://data.daff.gov.au/ data/warehouse/pel_abares20110914.01/RR11.07\_PubInvAgRandD.pdf.

Sims, C., Stock, J. and Watson, M. (1990). Inference in linear time series models with some unit roots. Econometrica 58: 113-44. 
Sparger, J. A., Norton, G. W., Heisey, P. W. and Alwang, J. (2013). Is the share of agricultural maintenance research rising in the United States? Food Policy 38: 126-135, doi:10.1016/j.foodpol.2012.11.004, http://www.sciencedirect. com/science/article/pii/S0306919212001182.

Toda, H. Y. and Phillips, P. (1993). Vector autoregressions and causality. Econometrica 61: 1367-93.

Toda, H. Y. and Yamamoto, T. (1995). Statistical inference in vector autoregressions with possibly integrated processes. Journal of Econometrics 66: 225 - 250, doi:https://doi.org/10.1016/0304-4076(94)01616-8.

Townsend, R. and Thirtle, C. (2001). Is livestock research unproductive? Separating health maintenance from improvement research. Agricultural Economics 25: 177-189, doi:10.1111/j.1574-0862.2001.tb00198. $\mathrm{x}$, http://onlinelibrary.wiley.com/doi/10.1111/j.1574-0862.2001.tb00198. $\mathrm{x} /$ abstract.

Wang, S. L., Heisey, P. W., Huffman, W. E. and Fuglie, K. O. (2013). Public $\mathrm{r} \& ; \mathrm{d}$, private $\mathrm{r} \& ; \mathrm{d}$, and u.s. agricultural productivity growth: Dynamic and long-run relationships. American Journal of Agricultural Economics 95: 1287-1293, doi:10.1093/ajae/aat032.

Zivot, E. and Andrews, D. W. K. (1992). Further evidence on the great crash, the oil-price shock, and the unit-root hypothesis. Journal of Business 83 Economic Statistics 10: 251-270. 